\title{
Sobre las posibles referencias egipcias del Mito de las Edades de Hesíodo. Algunos documentos para el estudio de su génesis y estructura
}

\author{
Roque Lazcano Vázquez ${ }^{1}$
}

Recibido: 22 de Febrero de 2019 / Aceptado: 6 de Septiembre de 2019

Resumen. En el presente artículo se explora la posibilidad de que las principales referencias extranjeras del Mito de las cinco Edades-Razas de Hesíodo proviniesen de Egipto -aunque filtradas a través de la cultura minoica-micénica-, y no, como por lo general se viene sosteniendo, de Mesopotamia. No se afirma que este mito, tal y como lo presenta Hesíodo, tuviese un homólogo previo en Egipto; solo se propone que algunos de los elementos que lo coordinan podrían inspirarse en tradiciones egipcias: particularmente, la idea de las cinco estirpes originarias (que Hesíodo historiza) y la distinción de los cuatro tipos de seres que las caracterizan. Contenidos similares se encuentran en Manetón (s. III

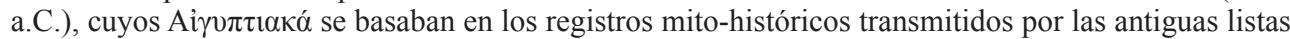
dinásticas, de las cuales el Canon Real de Turín ( $c a$. s. XIII a.C.) es la mejor conservada. Guiados por este parecido, y apoyados en las reliquias que constatan el diálogo secular entre Grecia, Creta, Micenas y la región del Nilo, investigaremos otras tradiciones egipcias que pudieron influir en la elaboración del Mito de las Edades.

Palabras clave: periodización primitiva; Mito de las Razas; Manetón; listas de faraones; Canon Real de Turín; diálogo Grecia-Egipto; Edad de Oro/Edad de Hierro.

\section{[en] On the possible Egyptian references of Hesiod's Myth of the Ages. Some documents for the study of its genesis and structure}

\begin{abstract}
This article explores the possibility that the main foreign references of Hesiod's Myth of the five Ages-Races came from Egypt -though filtered through the Minoan-Mycenaean culture-, and not, as it is generally assumed, from Mesopotamia. It is not claimed that this myth, as presented by Hesiod, had a previous counterpart in Egypt; it is only proposed that some of the main elements that coordinate it could come from Egyptian traditions: namely, the idea of the five original tribes (which Hesiod historicizes) and the distinction of the four types of beings that characterize them. Similar Egyptian

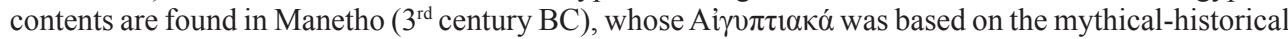
records transmitted by the ancient dynastic lists, of which the Turin Royal Canon (ca. XIII century BC) is the best preserved. Guided by this parallelism and supported by the relics that confirm the secular dialogue between Greece, Crete and the Nile region, we investigate other Egyptian traditions that could influence the elaboration of the Myth of the Ages.
\end{abstract}

Keywords: primitive periodization; Myth of the Races; Manetho; lists of Pharaohs; Turin Royal Canon; Greece-Egypt dialogue; Golden Age/Iron Age.

1 Universidad de Santiago de Compostela

roqelazcanovazquez@gmail.com

ORCID iD: https://orcid.org/0000-0001-8392-3035 
Sumario. 1. Introducción. 2. Estado de la cuestión. La hipótesis de la influencia oriental. 3. Presencia egipcia en la Hélade arcaica. 4. Percepción de Egipto en la antigua Grecia. 5. Hesíodo y la antigua literatura egipcia. 6. Egipto y el Mito de las Edades de Hesíodo. 7. Las cinco estirpes de Manetón y las listas de reyes egipcias. 8. Conclusiones.

Cómo citar: Lazcano Vázquez, R. (2020) Sobre las posibles referencias egipcias del Mito de las Edades de Hesíodo. Algunos documentos para el estudio de su génesis y estructura, en Cuadernos de Filología Clásica. Estudios griegos e indoeuropeos 30, 65-94.

\section{Introducción}

Los documentos periodográficos más antiguos que se conservan son las listas de reyes sumerias y egipcias, una serie de inscripciones sobre piedra y papiro en las que se combinan registros históricos con relatos mitológicos y dataciones desorbitadas. Asímismo, en las antiguas sociedades que fueron organizando estos datos del pasado se elaborarían mitos originarios con los que se pretendía explicar la historia reciente remontándose muy atrás en el tiempo, como es el caso del poema de Gilgamesh, el poema de Atrahasis o el Mito de la Vaca Celeste. Pero en la literatura de este género que nos ha llegado no encontramos ningún ejemplo de una periodización que divida el relato histórico en cinco épocas claramente diferenciadas y degradadas a partir de una edad de oro, como sucede en Los Trabajos y los Días.

En este sentido, el Mito de las edades-razas metálicas de Hesíodo constituiría la primera historización formalizada en base a un esquema quinario que conservamos ${ }^{2}$,

2 Hesíodo, Los trabajos y los días, 100-201 (trad. Pérez Jiménez \& Martínez Díez 1978: 130-134). No obstante, la división en cinco periodos se encontraba antiguamente también en otras escalas temporales. Por ejemplo, aunque Homero emplea una división de la noche en tres partes (vigilias), en Estesícoro (ca. 630-550 a.C.), Simónides y el Reso de pseudo-Eurípides (versos 545 y 563-564) encontramos una división en cinco vigilias (West 1999: 27). Por su parte, en el Jorda Avesta zoroástrico aparece una división de la jornada laboral en cinco rezos (los gāhs): «Los Gahs son las cinco divisiones del día. El Havani de las 6 a las 10, el Rapithwina de las 10 a las 15, el Uzayeirina de las 15 a las 18, el Aiwisruthrima de las 18 a las 24, el Ushahina de las 0 a las 6». Vid. «Gâhs» en Jorda Avesta (en trad. Mills 1887: 379). Y una división quinaria similar es la que se relata en la «Parábola de los obreros de la viña» de Mateo 20: 1-16. Esta división regirá también el calendario monástico, que desde el alto medievo hasta el siglo XIV constituiría la medición por excelencia del tiempo del Occidente cristiano a través de la Iglesia. En su comentario al Evangelio de Mateo, Orígenes se basa en la división de la jornada laboral que relata la parábola («porque el reino de los cielos es semejante a un hombre, padre de familia, que salió por la mañana a contratar obreros para su viña») para establecer los cinco periodos de la historia sagrada, cada uno de los cuales se iniciaría con el nacimiento de uno de los siguientes personajes: Adán, Noé, Abraham, Moisés y Cristo. La anamórfosis origenista reside en que cada llamada de nuevos trabajadores en la parábola de Mateo corresponde a una nueva alianza de la humanidad con Dios en la lectura de Orígenes (Van der Pot 1999: 172-173). Estos cinco periodos se encuentran también en Gregorio Magno (ca. 540-604), quien los suscribiría en una homilía: «La mañana del mundo dura de Adán a Noé, la tercera hora de Noé a Abraham, la sexta hora de Abraham a Moisés, la novena de Moisés a la venida del Señor, la undécima de la venida del Señor al fin del mundo» (Gregorio Magno, Homiliae in Evangelia, I, homilia XIX, citado en Le Goff 1991: 35). Se podría pensar que Hesíodo realizó una transformación similar a la propuesta por Orígenes (i.e., aplicar la división quinaria del día al conjunto de la historia), pero nada indica que la ideación hesiódica haya seguido estos cauces. En cuanto a la división del año en cinco periodos, los hindúes mencionan en varios textos «cinco estaciones» (las cuatro nuestras más la lluviosa): cf. Taittirīya saṃhitā, I, 6.1c-g; Chandogya Upanishad, II.5.1, pero carecemos de textos antiguos que muestren una aplicación de esta división a la historia. Por otro lado, la primera aplicación del mito de las edades del hombre (cinco también) a la historia universal (encarnada en el imperio) se debe a Séneca (fr. 99; Lactancio, Instituciones divinas, VII, 15.14-19) -véase también Floro, Epitome, I, 4 ss.-. Asímismo, Fírmico Materno (Mathesis 3.1.11-15) fue uno de los primeros en recurrir a la «influencia astrológica» de los cinco planetas conocidos en la antigüedad (Saturno, Júpiter, Marte, Venus y Mercurio) para 
siendo, además, uno de los mitos periodológicos más influyentes en el imaginario occidental, de repercusión solo comparable a la ejercida luego por las periodizaciones judeocristianas y marxistas (con las que comparte la idealización de unos orígenes desalienados y, dependiendo del enfoque, también la división de la historia universal en cinco épocas $\left.{ }^{3}\right)$.

La mayor parte de las teorías sobre el origen del mito de las edades oscilan entre las que atribuyen su entera ideación al propio Hesíodo -quien habría partido de los contenidos ofrecidos por la cultura helénica, donde ya eran comunes los metales con los que caracteriza a cada raza-y las que sostienen que el poeta habría adaptado un esquema proveniente de Mesopotamia, Persia o la India. No obstante, que sepamos, nadie había incidido aún en la posibilidad de que la principal referencia cultural de este mito fuese Egipto ${ }^{4}$ (como sí se ha sugerido de otros mitos de Hesíodo), en cuya tradición se pueden rastrear varios paralelismos con algunos de sus contenidos.

A nuestro juicio, es difícil de explicar que, habiéndose comparado el Mito de Hesíodo con la Lista Real Sumeria, no se haya hecho lo propio con las listas de faraones egipcios ${ }^{5}$, ni se haya reparado en los testimonios de la cronografía egipcia que recoge Manetón en su Historia de Egipto (Aegyptiaca, III a.C.), la cual se basaba en listas de reyes como la transmitida por el Canon Real de Turín, cuyo papiro se ha datado en la época de Ramsés II ( $c a$. XIII a.C.). En estas listas, los reyes-dioses se agrupan en épocas mitológicas previas a los registros históricos con el objetivo de establecer una conexión legitimadora con un primer gobierno divino a partir del que se sucederían diferentes géneros de dinastías, algo muy similar a lo que realiza Hesíodo en su mito. Sin embargo, de las ediciones de la Historia de Manetón que hemos podido consultar ${ }^{6}$, solo una -la reciente traducción española de Jiménez Fernández

dividir la historia en cinco fases (Most 1997: 106, afirma equivocadamente que la de Firmico supone la primera historización posterior a Hesíodo que se divide también en cinco eras: tanto la de Orígenes como la de Séneca y Floro -e incluso la doctrina de «las cinco venidas» maniquea: Kephalaion 16 [55,11]; 25 [76, 15-25]- son anteriores). Por lo demás, tanto en la antigua Persia como en el antiguo Egipto, el calendario anual de 360 días se completaba añadiendo cinco días, los epagómenos, frecuentemente identificados con cinco deidades (en el caso de la cosmogonía del Libro de los muertos, con los cinco hijos de Geb y Nut -o de Rea, según Plutarco, $L a$ desaparición de los oráculos $429 \mathrm{f}-$ ).

3 El quinto reino cristiano tras los cuatro imperios ( $c f$. P. Orosio, Historiae...; E. Jerónimo, Commentariorum in Danielem Prophetam...; Eytzinger, Pentaplus regnorum mundo; António Vieira, Historia do futuro; los manifiestos de los Fifth Monarchy Men de Inglaterra, etc.), los cinco mundos -olamot- sucesivos de la Cábala judía; las cinco edades de la humanidad según Jenish (Universalhistorischer Ueberblick der Entwickelung des Menschengeschlechts), Fichte (Grundzüge des gegenwártigen Zeitalters), Hegel (Vorlesungen über die Philosophie der Geschichte) o Gebser (Ursprung und Gegenwart); los cinco modos de producción de Marx, etc. Por lo demás, la división en cinco periodos se ha aplicado a otro tipo de procesos que podrían ser susceptibles de utilizarse como primeros analogados de una metafísica Historia Total desde ciertas perspectivas idealistas: el desarrollo psicocognitivo de los cinco niveles de la «autoconciencia» (Rochat 2003); las cinco edades del universo según los cosmólogos metafísicos (Adams-Laughin 1999); las cinco épocas de la evolución energética de las formas biológicas (Judson 2017); los cuatro eones geológicos más el postrimero Antropoceno, etc. Para una crítica de la idea de Historia que prevenga de su mistificación, remitimos a Bueno (1992).

$4 \quad$ A excepción, quizás, de Koenen (1994).

5 Un reciente trabajo sobre los orígenes de nuestro sistema de épocas recoge el Canon de Turín y el Mito de las Edades de Hesíodo prácticamente seguidos, pero no desarrolla sus posibles vinculaciones históricas (Kamp 2010: 19-24). También en el capítulo «Ages of the World» de la ERE de Hastings-Selbie-Gray (1908: 192) se citan ambas periodizaciones en la misma página por razones puramente alfabéticas (la cosmología de Egipto sería inmediatamente anterior a la de Grecia), pero sin proponer alguna influencia.

6 Unger (1867); Bovet (1835²); Waddell (1964); Verbrugghe y Wickersham (1996); Vidal Manzanares (1992); Jiménez Fernández \& Jiménez Serrano (2008). 
y Jiménez Serrano- alude en una breve nota al mito hesiódico ${ }^{7}$, pero sin desarrollar su posible vinculación histórica con la tradición egipcia, ni relacionarlo con algún contenido concreto de los fragmentos. Y, en lo tocante a las ediciones de la Lista Real del Papiro de Turín, la ausencia de alusiones parece total ${ }^{8}$.

\title{
2. Estado de la cuestión. La hipótesis de la influencia oriental ${ }^{9}$
}

\author{
Dentro del corpus de estudios sobre el Mito de las Edades de Hesíodo podemos \\ distinguir sobre todo dos bloques: el de los trabajos filológicos y estructuralistas que \\ parten del foco intracultural emitido por las obras homéricas ${ }^{10}$, y el de aquellos que
}

7 Jiménez Fernández \& Jiménez Serrano (2008: 79): «Cfr. Hesíodo, Los trabajos y los días, 122, quien distingue claramente los diversos grados de los seres racionales: dioses, démones, héroes y hombres. Sobre la sucesión de los dioses en la teogonía egipcia, en Diodoro, en el Canon de Turín y en los diferentes fragmentos de Manetón, cfr. Helck (1956, p. 8)».

8 De los fragmentos recogidos en 1824 por Champollion, Gardner Wilkinson publicó en 1851 una edición inglesa, y en 1959 aparecería una nueva de Gardiner. Además de sus estudios introductorios, los trabajos de referencia sobre las dinastías de este papiro - puestas en relación con las que aparecen en los fragmentos de Manetón-son los de Helck (1956) y Meyer (1904). Resulta extraño que en ninguno de estos estudios se mencione el Mito de las Edades de Hesíodo, si bien recientes tratamientos del papiro han introducido algunos matices, lo cual podría llamar a la precaución: según Ryholt (2004), la desigual cantidad de información que se proporciona de cada reinado y época sugiere que el autor del Canon de Turín compiló datos de diferentes fuentes, con lo que en el papiro, en lo tocante a los reyes históricos, se podrían distinguir cinco secciones. La sección A del Canon de Turín, relativa al periodo arcaico, se correspondería con la primera y la segunda dinastías recogidas por Manetón, de cuyos reinados se proporcionan los años, los meses, los días y las edades de fallecimiento de sus reyes; la sección B, relativa al Reino Antiguo, incluye los reyes que Manetón sitúa entre la tercera y la sexta dinastía, e informa solo sobre los años de su reinado; la sección C incluiría hasta la décima dinastía de Manetón, informando sobre los años, los meses y los días de sus reinados; la sección D la conformaría el primer periodo intermedio de Tebas, la decimoprimera dinastía considerada por Manetón, de la que se reportan únicamente los años de reinado; y, finalmente, la sección E incluiría el reino medio y el segundo periodo intermedio que llega, en la clasificación de Manetón, hasta la decimosexta dinastía, y nos informa sobre los años, los meses y los días de sus reinados. Para un resumen, véase tabla 4 en Reyholt (2004: 146). Véase también: https://pharaoh.se/ royal-canon-of-turin-kinglist.

9 Sobre las diversas fuentes del ingenio de Hesíodo, nos parece que Adrados (2001: 198) ofrece una hipótesis razonable. Según el helenista, la Teogonía supone la expansión de un género oriental que comprendía un breve proemio y un poema en el que se unían cosmogonía y teogonía. Éste habría llegado a Grecia ya en fecha remota, como se aprecia en el formulario que emplea Hesíodo. Por su parte, Trabajos y días representaría la expansión del género proverbial en el que se daban cita parénesis, fábulas, símiles, mitos, máximas, etc. A su vez, el Catálogo y el Escudo tendrían sus precedentes en la poesía genealógica y la épica. Al parecer, la genealogía era un género difundido en Beocia antes de Homero, y Hesíodo no hizo más que apropiárselo para confeccionar la Teogonía y el Catálogo -de hecho, en los poemas cosmogónicos-teogónicos hay un indicio de poesía genealógica- ( $c f$. West 1985: 4s; sobre la épica griega arcaica, vid. West 2003). Así como Homero compuso la gran epopeya a partir de pequeños poemas épicos, Hesíodo compuso la gran Teogonía (sobre el mundo natural y divino), la gran obra parenética (Trabajos y días, sobre el mundo humano) y el gran Catálogo. Hesíodo los dota de una nueva estructura formada por un proemio que anticipa el contenido y un relato dividido en bloques ordenados (ora cronológicamente, ora temáticamente).

10 Meyer (1910); Mazon (1912); Hartmann (1915); Goldschmidt (1950); Vernant (1960); Leclerc (1993); Verdenius (1985); Blaise et al. (1996); Sauzeau \& Sauzeau (2002). El estudio filológico moderno del mito de las edades se inicia con Buttman en 1814, mientras que con Goldschmidt da comienzo el análisis «estructuralista». J.-P. Vernant sustituiría las tres categorías de V. Goldschmidt por las tres funciones indoeuropeas de Dumézil: tres pares de razas (duplicando la de hierro - en la que se distinguen entre justos y desmesurados-) que representarían la función real, la función guerrera y la función productiva. Sauzeau \& Sauzeau (2002: 277ss.), frente a este trifuncionalismo, proponen añadir un cuarto término y crear un cuatrifuncionalismo, estableciendo un paralelismo con los cuatro caballos coloreados del Apocalipsis de Juan. El análisis estructuralista de este mito será criticado por autores como Ballabriga (1998). 
estudian sus posibles fuentes e influencias foráneas ${ }^{11}$, siendo un lugar común la referencia a las tradiciones cíclicas de Persia y la India ${ }^{12}$. En esta última línea, también se han señalado algunos paralelismos entre la Teogonía de Hesíodo y los mitos hititas de Kumarbi y Ullikummi (ca. 1400- 1200 a.C. $)^{13}$, así como entre el Mito de Pandora de Los trabajos y los Días y el mito sumerio de Pickax o "canción del sacho» ( ca. III milenio a.C.), la épica de Gilgamés (III milenio a.C.), la épica de Atrahasis (ca. XVIII a.C.), y el mito de Enki y Ninmah (II milenio a.C., probablemente inspirado en la épica de Atrahasis) ${ }^{14}$.

En respaldo de estas posibles referencias, Penglase (1994: 5-6) destaca sobre todo dos periodos en los que la influencia oriental en Grecia fue significativa. El primer periodo coincidiría con la época micénica antigua (XIV-XIII a.C.), cuando los griegos establecieron asentamientos en ciudades como Tarso y el noroeste de Siria. El segundo periodo se iniciaría tras la llamada edad oscura (XIII-VIII a.C.), a partir de mediados del siglo IX, y sus efectos más visibles serían los rasgos orientalizantes de las obras del arte griego de la época (730-630 a.C.). Aunque unos hallazgos de Lefkandi en Eubea demuestran que también durante la edad oscura existía cierto contacto con oriente, éste se habría intensificado sobre todo tras la expansión del Imperio Asirio hacia el oeste con las conquistas de Tiglatpileser III (745-727 a.C.).

A la luz de estos registros, cabría pensar que Hesíodo se sirvió de cosmologías cíclicas en base a cuatro edades procedentes de Persia ${ }^{15}$ y la India en el momento de

11 Griffiths (1956); Walcot (1966); West (1978); West (1993); Burkert (1992); Penglase (1994); Koenen (1994); Most (1997); Rutherford (2009). Las posiciones límite se debaten entre quienes defienden que Hesíodo adapta uno de los mitos cíclicos orientales, al que únicamente habría añadido la edad de los héroes o la de hierro como broche original, y quienes sostienen que incluso el mito del edén originario es de invención hesiódica.

12 Al menos desde la discusión de Roth (1860), y que continuará con Wilamowitz (1928). También en los estudios introductorios al mito de las edades de las ediciones de las obras completas de Hesíodo que hemos podido consultar: Cassanmagnago (2009); Ercolani (2010); West (1978); Sinclair (1979).

13 Bernabé (2000). El nexo podría haberse producido a través de Creta. Vid. Walcot (1966: 137, n. 51).

14 Walcot (1966: 55-79). Sobre el posible origen oriental del mito de Prometeo, vid. Duchemin (2000).

15 En la doctrina zoroástrica del Mazdeísmo (ca. s. VI a.C.), según se expone en los libros pahlavi Bundahishn y Zātspram (ambos escritos en el siglo IX d.C., aunque presumiblemente basados en textos del Avesta de entre los siglos V y III a.C.), Ahura Mazda (Ormazd, el dios del bien) habitaría la «luz sin comienzo», y Angra Mainju (Ahriman, el dios del mal), separado de él, se encontraría en la «oscuridad sin fin». La cosmogonía zoroástrica relata la creación del mundo por parte de Ormazd, la mezcla y lucha de ambos principios durante 6.000 años, y la victoria final de Ormazd, con la que ambos principios se vuelven a separar y se restituye la pureza originaria. La primera recopilación completa de esta cosmogonía se debe a los historiadores armenios Elise Vardapet y Eznik de Kolb (siglo V d.C.; copias del XII), pero varios siglos antes, en el IV a.C., Teopompo, Aristóxeno y Eudemo de Rodas ya habían dejado constancia de ella. Ya que Zoroastro inauguraba el último periodo de 3.000 años, es probable que el primer periodo, «antes de la creación del mundo», quedase «fuera del tiempo» en muchas de las dataciones (de ahí la variabilidad entre los 9.000 y los 12.000 años de duración cosmogónica según los textos): el gran año cósmico se dividiría, pues, en tres o cuatro etapas de 3.000 años cada una. Durante los primeros 3.000 años, la creación se mantiene en un estado de espiritualidad pura. Al principio del segundo periodo, Ormazd crea el mundo corpóreo. En este periodo reina la pureza hasta que aparece Ahriman. Durante el tercer periodo de 3.000 años, el mal y el bien se mezclan, de modo que el mundo queda contaminado de mal. Sin embargo, al final de este ciclo hace su aparición Zaratustra, fundando una nueva religión y restaurando la fuerza del bien (Ormazd) en el mundo. Al principio de los últimos 2.000 años comienza a brillar el sol y al final de los 12.000 años llega el fin del mundo, depurado ya de toda sombra. Los muertos resucitan y la tierra vuelve a su pureza espiritual originaria. $C f$. Van der Pot (1999: 300-301). Para una exposición más detallada, véase Hastings-Selbie-Gray (1908: 205-210); o la Encyclopaedia iranica: http:/www.iranicaonline.org/articles/ cosmogony-i. Al parecer, podrían haber sido los magi zurvanitas, inspirándose en la astrología zodiacal, quienes fijaron el periodo cosmológico en 12.000 años divididos en cuatro periodos. Según West (1971: 32), esta concepción cosmológica se habría establecido en Persia en torno al siglo IV a.C., y seguramente se pueda retrotraer al siglo anterior, pero no mucho más allá. 
elaborar su particular mito, añadiendo la Edad de los Héroes para reexponerlo desde la perspectiva de la religión griega. Pero lo cierto es que la cosmología de las cuatro edades todavía no se había teorizado en los antiguos textos indoiranios que nos han llegado. En los Vedas no se alude todavía al sistema de las cuatro yugas ${ }^{16}$ que se popularizaría en la literatura hindú posterior, principalmente con el Mahabharata, las Leyes de Manu y el Visnú Purana (escritos entre el III a.C. y el II d.C.) ${ }^{17}$. Por otro lado, tanto los Avestas zoroástricos como el judío Libro de Daniel ${ }^{18}$, aunque puedan

16 Véase «Yuga» en Macdonell \& Keith (1912: 192-193).

17 No sabemos si por influencia de los magi, pero en las Leyes de Manu hindúes (ca. 200 a.C.) el año de Brahman se divide en cuatro fases: «Pero escucha ahora la breve (descripción de) la duración de una noche y un día de Brahman y de las respectivas edades (del mundo, yugas) según su orden./ Ellos declaran que la edad de Krita (consiste en) cuatro mil años (de los dioses); el ocaso que la precede consiste en varios cientos de años, y el ocaso que la sucede es del mismo número./ En las otras tres edades, con sus ocasos precedentes y subsiguientes, los miles y cientos de años se ven disminuidos en uno (cada uno)./ Estos doce mil años que acabamos de mencionar como el total de cuatro edades (humanas), se llaman una edad de los dioses./ Pero sepas que la suma de mil edades de los dioses hacen un día de Brahman, y que su noche es de la misma duración./ (Solo) aquellos (que) saben que el sagrado día de Brahman, de hecho, termina tras (la consumación de) mil edades (de los dioses) y que su noche es igualmente larga, son hombres que de verdad están familiarizados con la duración de los días y las noches». Vid. Las Leyes de Manu, I, 68-73 (traducido a partir de Bühler 1886: 20-21). El sistema también se expone en el Mahabharata: «Tras la disolución del universo, toda esta hermosa creación vuelve a la vida. Cuatro mil años se ha dicho que constituye la Krita Yuga. Tanto su amanecer como su ocaso se dice que duran cuatrocientos años. La Treta Yuga se ha dicho que comprende tres mil años, y su amanecer, así como su ocaso, se dice que comprende trescientos años. La Yuga que viene después se llama Dwapara, y se ha calculado que consiste en dos mil años. Su amanecer, así como su ocaso, se dice que comprende doscientos años. La siguente Yuga, llamada Kali, se dice que comprende mil años, y su amanecer, así como su ocaso, se dice que comprende cien años. Sepa, Oh rey, que la duración del amanecer es la misma que la del ocaso de una Yuga. Y después de que la Kali Yuga se termine, la Krita Yuga vuelve de nuevo. Un ciclo de Yugas, por tanto, comprende un periodo de doce mil años. La compleción de mil de estos ciclos, constituye un día de Brahma. / Oh rey, hacia el final de los miles de años que constituyen las cuatro yugas, y cuando las vidas de los hombres se vuelven tan cortas, se produce una sequía que se extiende durante muchos años. Y luego, oh señor de la Tierra, el hombre y las criaturas, dotadas de poca fuerza y vitalidad, padecen hambruna y mueren por miles». Vid. Mahabharata, III.188, a partir de Chandra Boy (1884). Cf. también Mahabharata, II, 234; III, 148-9. La doctrina aparecerá varios siglos después en el Vishnú purana (I.3) sin apenas modificaciones.

18 Libro de Daniel, II 31-44, donde el profeta habría desentrañado el futuro de los imperios a partir de la interpretación de la estatua metálica que aparecía en un sueño del rey caldeo Nabucodonosor II (VI a.C.). El neoplatónico Porfirio (ca. 232- 304 d.C.) fue el primero en señalar que el Libro de Daniel no había sido escrito en el siglo VI a.C., sino posteriormente a los eventos que decía prever (vaticinium ex eventu), en el siglo II a.C., por un judío que vivía en la época de Antíoco Epífanes, rey de Siria entre ca. 175 y 164 a.C. [Porfirio de Tiro, Contra los cristianos, Libro II, fr. 30]. Antíoco fue el último rey de la época de esplendor del Imperio seleúcida, identificado por muchos intérpretes con el cuarto de los reinos profetizados por Daniel. El primero de éstos habría sido el Imperio asirio-babilónico de Nabucodonosor (cabeza de oro de la escultura), seguido por el Imperio medo-persa (pecho y brazos de plata), luego por el Imperio greco-macedonio (vientre y muslos de bronce) y el Imperio seleúcida (piernas de hierro). Posteriormente se daría un Imperio que muchos asocian con el romano, el cual sería derrotado (o reforzado) por el advenimiento del reino de Dios en la tierra, a saber, la Iglesia [así en el comentario de Jerónimo al Libro de Daniel]. Al margen de todas estas especulaciones, lo interesante es que el Libro de Daniel, aunque hubiera sido escrito en el siglo pretendido por los exégetas cristianos (VI a.C.), seguiría siendo posterior a la obra de Hesíodo. Lo cual tampoco significa que la influencia haya sido inversa. Además, en otras latitudes y épocas también encontramos similitudes: el himno X, 90 del Rig Veda narra la creación del mundo a partir del cuerpo de un ser primordial (el purusha), cuyas partes se corresponderían con cuatro castas sociales: la boca se convirtió en el brahmana (el sacerdote); los brazos, en el rajanya (el guerrero); los muslos, en el vaishya (el comerciante); y los pies, en el shodra (el servidor). Aunque esta antropomorfización de la sociedad recuerda un poco a la estatua del Libro de Daniel, en ella no encontramos división en reinos o imperios, ni mucho menos en edades históricas, de ahí que las fuentes de Daniel puedan situarse en otras tradiciones. Uno de los modelos visionarios más similares podría situarse en un libro perdido del Avesta persa, el Bahman Yast, cuyo contenido nos llega a través de comentarios Pahlavi de la época helenística (ca. 300-50 a.C.). En el capítulo 1 del Zand-i Bahman Yasn se relata un sueño enviado al profeta Zoroastro por el dios de la luz y la bondad, Ahura Mazda, en el que aparece un árbol con 
recoger tradiciones más antiguas, se escribieron bastantes siglos después de la obra de Hesíodo.

La doctrina de las yugas y el mito de las edades hesiódico coinciden en el recurso a un esquema degenerativo en el que la última época está plagada de males. La diferencia radica en que el esquema de Hesíodo no es cíclico, ni anuncia una nueva edad de oro. Además, en la teoría hindú de las yugas, al contrario del mito hesiódico y las profecías de Zaratustra y Daniel, no hay simbolismo metálico ${ }^{19}$. En su lugar, las edades se distinguen con cuatro colores (blanco, rojo, amarillo y negro), de forma similar a como hacían los chinos ${ }^{20}$.

Griffiths (1956) ha propuesto que la degradación metálica expuesta por Hesíodo se podría acoger al sucesivo orden de descubrimiento de estos metales ${ }^{21}$. Siguiendo a Forbes, Griffiths alega que el hecho de que el oro y la plata puedan encontrarse en su estado natural con más facilidad que otros metales, habla en favor de que fueran los primeros en descubrirse, y así parece que fue en Irán, Mesopotamia y China,

cuatro ramas (de oro, de plata, de acero y de hierro "mezclado"). Ahura Mazda le explica que representan las edades-reinos del mundo futuro: «Zorastro le pidió inmortalidad a Ahura Mazda; entonces, Ahura Mazda desplegó su omnisciente sabiduría a Zoroastro, quien, a través de ella, contempló la raíz de un árbol en la que había cuatro ramas, una de oro, otra de plata, otra de acero, y otra mezclada con hierro ... Ahura Mazda habló así a Zoroastro el Spitama: «Esa raíz de árbol que ves, y esas cuatro ramas, son los cuatro periodos que vendrán. La dorada representa cuando tú y yo hablamos, y el rey Vistap aceptará la religión, y demolerá las imágenes de los demonios ... Y esa de plata es el reinado de Ardacher, el rey Kayan (Kai Sha), y esa de acero es el reinado del glorificado (anoshak-ruban) Khusro, hijo de Kevad, y esa mezclada con hierro es la maligna soberanía de los demonios, con sus pelos desgreñados de la raza de la ira, y cuando sea el final del décimo centésimo invierno (satô zim) de tu milenio, ¡Oh, Zoroastro el Spitama!». Cf. Bahman Yast, I, 2-5, traducido a partir de West (1880: 191-193). La alusión a Ardakhshir (Ardacher), el fundador del Imperio sasánida en el siglo III a.C., evidencia el carácter ex eventu de la 'visión' y dificulta su atribución a textos mucho más antiguos. En Bahman Yast, II, 14-22 se vuelve sobre esta profecía, ahora relatada en primera persona, en la que se añaden tres ramas más al árbol, dando lugar a un total de siete que también se hacen corresponder con metales (oro, plata, cobre, bronce, estaño, acero y hierro mezclado).

19 En griego, el término $\mu \varepsilon ́ \tau \alpha \lambda \lambda$ ov designaba en origen a la mina, pasando luego a nombrar los materiales que de ella se extraían (Sauzeau \& Sauzeau 2002: 261). Véase también Halleux (1974).

20 Sima Qian, Registros históricos, en Youlan (1989: 180-181). No deja de ser llamativo que, para simbolizar las edades del hombre, Hesíodo recurra a las diferentes especies del metal, un elemento que en cosmologías como la china formaría parte de las cinco potencias primordiales, pero que, en Grecia, sin embargo, nunca se incluye entre ellas. Además, Hesíodo también alude al otro elemento de la cosmología china, la madera, para señalar la procedencia degenerada de la tercera edad («nacieron de los fresnos»). Sería interesante estudiar el alcance histórico-antropológico de esta disensión cultural, ya que la metáfora metálica podría considerarse una suerte de prefiguración, sin duda muy rudimentaria, de la idea de 'cultura objetiva' moderna, aunque en la antigüedad fuera entendida, por lo general, desde una perspectiva un tanto 'rousseauniana': la cultura -la mezcla y modelación de los metales- como una perversión de la pureza primitiva, cuyos resultados 'objetivos' modifican y determinan las relaciones que los seres humanos mantienen tanto entre ellos mismos como con el entorno. No obstante, creo que sería erróneo identificar en Hesíodo una atribución clara de las transformaciones históricas de tipo moral a causas o razones meramente tecnológicas. Para la distinción de los conceptos de cultura, $c f$. Bueno (1996).

21 Una sugerencia controvertida, ya que no parece que las evidencias históricas apoyen semejante conciencia de los estratos arqueológicos en la Grecia arcaica, sobre todo si tenemos en cuenta que los posteriores autores griegos no hicieron esa lectura del mito hesiódico (como critica Baldry en 1956, quien había firmado un estudio precedente sobre el mito hesiódico -1952- al que también Griffiths responde -1958-). Griffiths (1956: 114), apoya su teoría en la afirmación de Heródoto (Historias, III 102, 116; IV 13, 27) de que el oro sería más abundante en las sociedades primitivas. Por otro lado, los griegos arcaicos carecían de término para distinguir el bronce y el cobre (algo que sucedía también en otras lenguas), pues a los dos los llamaban chalkós, lo que, según Griffiths, podría justificar que a la edad de los héroes no se asocie algún metal y funcione como una continuación de la de bronce; además, parece un hecho aceptado que la época homérica era abundante en este metal. Vid. Griffiths (1956: 113). 
donde los registros de oro se encontrarían entre los más antiguos ${ }^{22}$ (en Egipto, en cambio, parece que el descubrimiento del cobre precedió al del oro, si bien éste se ha encontrado ya en tumbas predinásticas ${ }^{23}$ ). A nosotros nos parece, más bien, que la ordenación que hace Hesíodo de los metales no representa otra cosa que su gradual depreciación.

Por su parte, West (1999: 319) sostendría que la metáfora metálica que observamos en Hesíodo, Daniel y los textos persas procedía de una fuente común ${ }^{24}$ cuya datación se estima en no antes de principios del primer milenio a.C. (es decir, no antes de la Edad de Hierro arqueológica ${ }^{25}$ ), y que se podría localizar en Mesopotamia o Urartu, regiones que gozaban de un mayor desarrollo metalúrgico en el periodo inmediatamente anterior a Hesíodo ${ }^{26}$. La alegoría de los metales se encuentra, en efecto, en varios textos antiguos, aunque no al servicio de representaciones "periodizantes"27. En el Antiguo Testamento, algunos profetas hebreos aluden a la impureza moral de las naciones con la metáfora de metales básicos y preciosos que Yahvéh mezcla y refina en su fuego ${ }^{28}$. También en las especulaciones esotéricas de los clérigos asirio-babilónicos (según tablillas cuneiformes conservadas en el British Museum) encontramos la asociación de los dioses primordiales con determinados metales: Anu sería la divina plata, Enlil el divino oro, Ea (antes Enki) el divino cobre y Ninazal el divino estaño ${ }^{29}$. En otros periodos de la religión babilónica, el dios Angal se identificaba con la plata, Enmesarra con el oro, Ea con el cobre, Ninmah con el estaño y el Anunaki con el «oro rojo» ${ }^{30}$.

22 Griffiths (1956: 113). Pero no sólo el oro, por lo que la suposición parece sesgada: «There are only four metals (gold, copper, meteoric iron and more rarely silver) which are found in sufficient quantity in their native state to rank amongst the earliest» (Forbes 1950: 140-141). En efecto, en las tumbas de pueblos indoeuropeos se han encontrado objetos hechos con estos materiales (armas de cobre y elementos de oro y plata) junto a objetos labrados en piedra, sílex o madera. Vid. Sauzeau \& Sauzeau (2002: 262-263).

23 Lucas (1945: 257). Según Forbes (1950:249), la metalurgia del oro, el cobre y el plomo era conocida en Mesopotamia e Irán (Tepe Hissar, Anau) antes de que consten conexiones con Europa.

24 La hipótesis se retrotrae a Reitzestein \& Schaeder (1926), siendo criticada por Nock el mismo año.

25 El Atharvaveda hindú (ca. XII-X a.C.) parece ser el primer texto sánscrito que menciona el hierro, denominándolo aias siama, «metal negro».

26 West (1999: 312).

27 La des-historización del mito hesiódico de las razas metálicas ya se encuentra en Platón (Crátilo 398a-e; República 415a-c; 344e), cuya anamórfosis quizás influyó en el aserto de Proclo (Scholia ad Hesiodum en Gaisford 1816: 90 ss.) de que el mito de las razas representa en el tiempo hechos atemporales. Véase Rosenmeyer (1957: 264-5). Esta es la idea que también defienden Goettling $\left(1878^{3}\right)$ y Miralles (1975) para las tres primeras razas, las cuales constituirían un bloque atemporal existente en mitos previos: Hesíodo las jerarquiza en función de su destino post mortem (el de los seres que los caracterizan). Cf. también Goldschmit (1950).

28 «Todos ellos son rebeldes empedernidos y andan calumniando; son bronce y hierro; todos ellos son corruptores. / Se quemó el fuelle; por el fuego se ha consumido el plomo; en vano fundió el fundidor, pues los malos no son arrancados. / Plata desechada los llamarán, porque Jehová los desechó» (Jeremías 6, 28-30); «... Hijo de hombre, la casa de Israel se me ha convertido en escoria; todos ellos son bronce, y estaño, y hierro y plomo en medio del horno; escoria de plata son. / Por tanto, así ha dicho Jehová el Señor: Por cuanto todos vosotros os habéis convertido en escoria, por tanto, he aquí que yo os reuniré en medio de Jerusalén. / Como quien junta plata, y bronce, y hierro, y plomo y estaño en medio del horno, para encender fuego en el para fundirlos; así os juntaré en mi furor y en mi ira, y os juntaré allí y os fundiré. / Y os juntaré y soplaré sobre vosotros en el fuego de mi furor, y en medio de él seréis fundidos. / Como se funde la plata en medio del horno, así seréis fundidos en medio de él; y sabréis que yo, Jehová, habré derramado mi enojo sobre vosotros» (Ezequiel 22, 17-22).

29 CT 2449 (K 4349) E 3-6. Citado en Livingston (2007: 182). Véase también CT XX. 49.1.36; Forbes (1966: 76).

30 En ocasiones, estas divinidades se hacían corresponder con regiones del cosmos. Así en la compilación esotérica de Kisir-Assur (mediados del siglo VII a.C.), en la que se divide el mundo en seis regiones graduales: tres cielos y tres tierras. Citado en West (1999: 139). Alfred Jeremías («Ages of the World (Baylonian)»), en Hastings, 
Aunque los paralelismos del mito de las edades de Hesíodo con otros mitos orientales sean sólo parciales, según West existen ciertas coincidencias que indican conexiones históricas. Para el británico, es improbable que el mito de las edades metálicas se hubiese gestado en Grecia:

It is true that Hesiod is centuries earlier than the oriental sources that tell of metals or of four ages. But the scheme appears quite alien to the general Greek view of the past as reflected in the whole corpus of epic and genealogical poetry. According to the general view, there was indeed a time of heroes stronger (but not longer-lived or more righteous) than ourselves, and perhaps even stronger ones before that. This age was not, however, demarcated from the times that preceded and followed it. The heroes' descendants live on as our kings. They were themselves descended not from a Golden race but from local nymphs or autochthonous progenitors like Pelasgus. This common mythology has, as we saw, been pressed into combination with the scheme of ages, but in a manner that leaves the separate origin of the latter distinct. Its very formalism is un-Greek ${ }^{31}$.

Según esto, Mesopotamia sería un buen lugar de origen del mito ya que estaba bien situada para que sus ideas se diseminasen con facilidad hacia los persas, los indios, los judíos y los griegos. Además, siempre según el británico, en el siglo VIII a.C. el principal contacto griego con oriente era semítico. West concluye que lo más probable es que el mito de las edades metálicas apareciese durante este siglo, y que quizás habría alcanzado Grecia siguiendo la ruta Nínive-KarkemishPosideion-Calcis-Beocia ${ }^{32}$.

En su comentario a Los trabajos y los días de Hesíodo, tras pasar revista a las tradiciones persa, india y hebrea, West (1978: 176) establece un paralelismo entre

Selbie \& Gray (1908: 184-187) relata que la tríada de la luna, el sol e Istar (no exactamente correlativa con la tríada de Anu -dios del cielo y las estrellas-, Bel -Enlil, dios del aire y la atmósfera- y Ea -Enki, dios de la tierra-, que se corresponderían con los símbolos zodiacos de Sin, Samas e Istar), que según la religión sumeria regían el curso de los acontecimientos, estarían asociados a tres metales: la plata, el oro y el cobre, respectivamente: «Silver is the metal of the moon, gold the metal of the sun, copper the metal of Istar. According to the reckoning which begins with the Age of the moon, the silver must have been the first Age, on which a less valuable then followed». Desde registros antiguos, los sumerios dividían la historia en dos edades (antes del diluvio y después del diluvio). Sin embargo, según Jeremías, con el reinado de Nabonasar (747-734 a.C.) habría comenzado una nueva edad, ya que el suyo fue el primer reino en cuyo inicio se registraron observaciones astronómicas (no obstante, esta perspectiva no sería la de los propios babilonios, sino la de un extranjero como Ptolomeo, quien recogerá este hito para establecer el año 1 de la era de Tot en Egipto). Con esta nueva era, la de Ram (ahora conocida como dinastía neobabilonia), daría inicio también la decadencia de Babilonia. Las dos edades anteriores habrían sido la «Era de los gemelos» (ca. 5000-2500 a.C.), con Nebo como principal divinidad, y la «Era del toro», en la que el trono del panteón divino fue transferido a Marduk, y que se habría iniciado con una reforma del calendario entorno al 2.800 a.C., cuando Babilonia se convirtió en la principal metrópoli mundial. Jeremías deja entrever la siguiente inferencia: si en cada una de estas épocas se adoraba particularmente a una divinidad, y si cada divinidad se asociaba con un metal, el terreno para la construcción del mito de las edades metálicas estaría abonado. Sin embargo, a nuestro juicio, el hermeneuta incurre en demasiadas asunciones que no se ven respaldadas por los documentos disponibles. Al parecer, también Gatz (1967) ha intentado probar estas tesis en su estudio sobre las antiguas asociaciones entre metales, colores y planetas, pero no hemos podido consultar el texto.

31 West (1978: 176-177)

32 Ibid., p. 177. En trabajos posteriores, West (1999: 312) redundará en esta hipótesis que Jeremías ya había sugerido en 1908, y que Griffiths reitera en 1956: lo más probable es que el mito de las edades metálicas haya tenido su origen en Mesopotamia. 
el mito hesiódico de las edades y la lista de los reyes sumerios ${ }^{33}$. Según la más antigua de estas composiciones inscritas en piedra, los reyes antediluvianos (columna I) habrían vivido durante miles de años (entre 10.800 y 72.000), pero la destrucción diluviana habría marcado el fin de esta era, propiciando un progresivo acortamiento de las vidas humanas. Así, los reyes de las primeras dinastías postdiluvianas verían sus reinados reducidos hasta aproximadamente los 1.200 años, cifra tampoco desdeñable, pero que se iría mermando con el paso del tiempo ${ }^{34}$. Entre las inscripciones de las columnas III y IV, la duración de los reinados ya se va normalizando (25 años, 36 años, etc.), aunque con excepciones que vuelven a los 360, 180, etc., generalmente en casos de reyes «divinos», al igual que la estirpe heroica en el mito de Hesíodo. Y lo mismo habría que decir de las siguientes: salvo remontadas puntuales, el tiempo de los reinados tiende a disminuir. En este sentido, desde la virtual perspectiva de Hesíodo se podría hacer una lectura de la lista sumeria en la tónica del famoso juicio de Tales respecto de la religión de su época («todo está lleno de dioses»): «todo está lleno de héroes». Es decir, el orden de sucesión «genética» que conecta a los humanos con los dioses desorienta, por lo que conviene depurar el esquema dando mayor compacidad a los contenidos de cada época.

En el poema acadio de Atrahasis, escrito en el siglo XVII a.C., y del cual se han hallado fragmentos datados en el siglo XIII en la ciudad de Ugarit -frecuente punto de contacto de Grecia con oriente--, también encontramos rastros de una periodización primitiva. Según Koenen ${ }^{35}$, la historia se podría dividir en cinco épocas: un primer periodo de 3600 años, previo a la creación de la humanidad (Tabla I, línea 37), seguido de tres periodos de 1200 años cada uno (I, 356, 416; II, $1^{36}$ ), y finalmente un quinto periodo tras la inundación. En este sentido, sugiere que la división zoroástrica en cuatro periodos de un total de 12.000 años podría ser una adaptación y transformación del antiguo paradigma babilonio ${ }^{37}$.

En lo relativo a la periodización interna, es cierto que en un punto intermedio del relato se mencionan «tres épocas» (tablilla II, III) ${ }^{38}$, pero, dados los fragmentos disponibles (y sus varias lagunas), no nos parece tan claro que la historia completa se divida en cinco periodos, como afirma Koenen ${ }^{39}$. Por otro lado, aunque puedan ras-

33 Al igual que Hartog (1990), West obvia las listas de reyes egipcios. Tampoco en los apéndices orientales a la obra de Lovejoy y Boas (1977: 431-456) escritos por Albright («Primitivism in Ancient Western Asia (Mesopotamia and Israel)») y Dumont («Primitivism in Indian Literature») encontramos alusión a la tradición egipcia.

34 A West se le escapa añadir que el legendario Etana (columna II) es una excepción en este esquema decadente, pues habría reinado 1.560 años, siendo, además, el rey sobre el que más datos se ofrecen. Cf. Canon Real Sumerio, Columna I, 1-5; 39-47; Columna II, 14-19 (ed. Jacobsen 1939).

35 Koenen (1994: 20-22).

$36 \quad C f$. Atrahasis en Dalley (1989: 18-29).

37 En el mito no se alude al progresivo deterioro del hombre a través de estas edades, pero sí se percibe un declive gradual de las relaciones entre dios y los seres humanos: los hombres son creados por mediación de Mami (la mujer de los dioses) para hacer los trabajos que originalmente hacían los dioses menores, los Igigi. Éstos, hartos de soportar el trabajo, se acaban revelando, y piden a Enlil ser sustituidos. Pero la creación de la humanidad tampoco solucionará los problemas, pues los hombres resultan ser muy ruidosos y perturban el descanso de Enlil, quien intentará destruirlos. Tras fracasar en sus dos primeros intentos -fracaso debido a la intervención de Enki en favor de la especie humana, pues dará consejos valiosos a Atrahasis-, Enlil enviaría la famosa inundación a la que sólo Atrahasis y su mujer sobrevivirían. Enki, entonces, desafiando al resto de los dioses, instó a Atrahasis y su mujer a que dejaran atrás sus posesiones y construyeran una barca con la que salvar a cuantos seres vivos pudieran, al modo del Noé bíblico. Con ellos daría inicio una nueva etapa de la humanidad.

38 Dalley (1989: 21).

39 Albright ha propuesto que en el total del poema (del que faltan muchos fragmentos) se producían siete intervenciones de Atrahasis, el "muy sabio", lo que coincidiría con siete apariciones de los siete sabios antes de la 
trearse paralelismos entre los mitos de Hesíodo y Atrahasis (la queja por el trabajo, por ejemplo), existen muchos temas centrales en el relato de Atrahasis que no tienen reflejo en el mito hesiódico de las edades -el periodo previo a la creación de la humanidad, la gran inundación, las dataciones, etc.- e, inversamente, algunos motivos centrales del mito de Hesíodo no aparecen en la canción acadia -la idealización de una primera edad en la que no se trabajaba, las diferentes estirpes, etc.-. Puesto que se han señalado también algunos paralelismos del poema de Atrahasis con la obra homérica (vid. supra), no conviene dejar de lado la hipótesis de su posible influencia en Hesíodo, ya que es probable que el poema llegara a conocimiento de los griegos durante el periodo orientalizante ( $c a$. 750-650 a.C.), si bien nos parece demasiado suponer su presencia en Los Trabajos y los Días.

Con todo, frente a la teoría de la influencia mesopotámica en Hesíodo ${ }^{40}$, un gran estudioso de la Grecia arcaica como Nilsson ${ }^{41}$ ya había insistido en que entre la literatura hesiódica y la mesopotámica había más diferencias que similitudes ${ }^{42}$, y que la influencia foránea en la obra del poeta era principalmente egipcia, aunque filtrada a través de las culturas minoicas y micénicas.

\section{Presencia egipcia en la Hélade arcaica}

Antiguamente, desde Egipto había rutas de caravanas a través del desierto del Sinaí que llegaban hasta Grecia ${ }^{43}$. Sin embargo, éstas se encontraban expuestas a la depredación de los beduinos, por lo que la vía de comunicación más frecuente era el mar, lo que propiciaría que las ciudades costeras se convirtieran en el principal lugar de cruce cultural. Por ejemplo, la influencia egipcia en los fenicios se aprecia sobre todo en la ciudad portuaria de Byblos. Otra línea iría por la costa de Libia hasta Creta, cuyo contacto con Egipto existía desde principios del tercer milenio a.C. En este sentido, la costa levantina y Creta funcionaban generalmente de punto intermedio, por lo que la relación entre Egipto y Grecia no era directa.

Las embarcaciones surcaban el Levante mediterráneo desde antes del 6.000 a.C., y el tráfico se habría intensificado en los milenios segundo y primero a.C. En esta

inundación. Ello daría un mínimo total de ocho periodos. De estos siete sabios hablan otros textos babilonios, pero la hipótesis no es convincente. Véase Lovejoy \& Boas (1977: 427).

40 Griffith (1956: 119) admite la existencia de una antigua identificación egipcia del oro con un metal divino, pero opina -como West- que el principal referente de Hesíodo procedía del ambiente metalúrgico sumerio: «It is clear that the Sumerians realized the importance of metals. A scheme of world-ages in which metals were ranged in order of discovery and linked with mythological material may well have arisen among them and been transmitted later to Babylon and Iran to form the basis of more elaborate and specialized interpretations such as appear in the Zoroastrian lore and the Book of Daniel. Such a scheme is more likely to have appeared in Sumeria than in Egypt. It is true that gold, in Egyptian eyes, had a special mystic significance. It appears in phrases like "star of gold" [Textos de las Pirámides, 889] and "sky of gold" [Papiro de Leiden, 350, 2, 5]; at the beginning of The Deliverance of Mankind it is said of Re that "his flesh was of gold" and "his bones of silver"; and the same is said elsewhere of others gods. [Erlman-Grapow, Wörterbuch, II, 238 (10)]. "Gold" is used frequently of goddess Hathor, and the phrase "gold of the gods" refers to her ["El halcón de oro" se refiere a Horus]. To the Egyptians, then, gold was a divine metal, the very stuff of the gods. And the gods, of course, are preeminently "the primordial ones". A comparable association, but not necessarily derived from Egypt, seems to colour Hesiod's depiction of the first age»».

41 Nilsson (1955); Nilsson (1961); Nilsson (1927).

42 Walcot (1966: 85). También Meltzer (1974) y Adrados (2012).

43 Para las fuentes de los datos que siguen, remitimos a la obra de West (1999: 3-9). 
época, Siria era el lugar en el que confluían todos los caminos (griegos, hititas, hurritas, mesopotámicos, egipcios). De este diálogo dan testimonio las tablillas en diferentes idiomas descubiertas en la ciudad portuaria de Ugarit, donde no se registran inscripciones griegas, pero sí cretenses. Ya en el tercer milenio, la plata y el bronce de la península ibérica llegaba a Mesopotamia, y al final de este milenio los egipcios usaban plata extraída de las minas del Ática. En vista de estas conexiones, no es sorprendente que los pueblos que se asentaron en el Egeo a mediados del tercer milenio hubieran absorbido elementos culturales del este asiático.

En el periodo de transición del heládico medio al tardío (ca. XVII a.C.), Creta era el principal canal de obtención de materiales para innovaciones en el cercano oriente. En la segunda mitad del s. XV a.C., los micénicos aumentaron su comercio y empezaron a colonizar otras regiones. Los egipcios, cuyo horizonte norteño había sido hasta el momento Creta, cobrarían entonces conocimiento de un lugar más distante llamado 'Tnyw' ${ }^{44}$. Éste aparece mencionado por primera vez en el año 42 del reinado de Tutmosis III ( $c a .1438$ a.C.): entre los obsequios del rey se incluye una vasija de plata de manufactura cretense ${ }^{45}$.

Durante los siglos que van hasta el 900 a.C. parece que hubo contacto regular, al menos entre Eubea y el este del mediterráneo. Un poco antes de mediados del siglo VIII se aprecia un aumento del volumen comercial, y, a mediados del siglo VII a.C., los griegos habrían contactado directamente con Egipto ${ }^{46}$. No obstante, las alusiones a la tierra del Nilo se encuentran ya en la obra de Homero que precede a Hesíodo. En la Ilíada sólo se hace referencia a la riqueza de la ciudad de Tebas (IX 381-384), pero en la Odisea las menciones son más numerosas y demuestran cierto conocimiento de

44 Quizás leído, según West, /Tanagu/, que sería tentador asociar con “Danaoi”. Vid. West (1999: 5).

45 Del contacto posterior hay más evidencias. Por ejemplo, del reinado de Amenofis III (ca. 1390-1352) se conserva un basamento de estatua con una lista de lugares de Ktfw (Creta) y Tnyw, en cuatro de los cuales (Festo, Cidonia, Micenas y Cnosos) se han encontrado objetos con inscripciones sobre Amenofis III y su reina Tiy, y existen evidencias de contacto micénico-egipcio también con su sucesor Akenatón (ca. 1352-1336). Un resumen de los registros de las antiguas relaciones entre Creta y Egipto puede verse en Milán Quiñones (2011). Véase también Duhoux (2003) y Ángel y Espinós (2007).

46 West (1999: 3-9). Al parecer, el logógrafo Hecateo de Mileto (ca. 550 - ca. 476 a.C.) fue uno de los primeros griegos en relatar de primera mano algunas de las tradiciones egipcias, siendo su obra el principal referente de Heródoto en estas cuestiones, aunque lo fuera para criticar algunas de sus observaciones: «Hasta este punto de mi relato, me informaron los egipcios y sus sacerdotes, indicándome que, desde el primer rey hasta ese sacerdote de Hefesto, que reinó en último lugar, había habido trescientas cuarenta y una generaciones humanas y, en ellas, otros tantos sumos sacerdotes y reyes ... Y por cierto que, cuando, con anterioridad a mi visita, el logógrafo Hecateo trazó en Tebas su genealogía y enlazó su ascendencia paterna con un dios en decimosexto grado, los sacerdotes de Zeus hicieron con él lo mismo que conmigo, aunque yo no les tracé la mía ... Y cuando Hecateo les trazó su genealogía y la enlazó en decimosexto grado con un dios, se la rebatieron en razón del número de las estatuas, sin aceptarle que un hombre hubiese nacido de un dios. Y le rebatieron su genealogía como sigue: afirmaron que cada uno de los colosos era un pirómis nacido de otro pirómis, hasta que le hubieron demostrado que los trescientos cuarenta y cinco colosos eran cada uno un pirómis nacido de otro pirómis; y no los enlazaron con dios o héroe alguno. (Por cierto que pirómis en lengua griega significa "hombre de pro"). Los sacerdotes, en suma, me hicieron ver que todos aquellos a quienes pertenecían las estatuas eran simplemente hombres y que estaban bien lejos de ser dioses; sin embargo, con anterioridad a los hombres que reinaron, fueron dioses - decían - quienes imperaron en Egipto conviviendo con los humanos y siempre era uno de ellos el que detentaba el poder. El último que reinó en el país fue Horus, hijo de Osiris, a quien los griegos denominan Apolo; él fue, tras deponer a Tifón [Seth], el ultimo dios que reinó en Egipto. (Osiris en lengua griega es, por cierto, Dioniso)» (Heródoto, Historia II, 142-144, en traducción de Schrader 1992: 434-437). La cosmogonía recogida por Heródoto, de posible influjo tebano, difiere de la de Manetón y de la del Canon de Turín, lo que sugiere que cada templo hacía su particular reconstrucción de la prehistoria dinástica. $C f$. Helck (1956: 5 y 7). Véanse también Froidefond (1971), Moyer (2002), Moyer (2011). 
la región: Menelao y Helena recibieron varios obsequios -entre los cuales una droga de mano de Polidamna, la esposa de Thon-, cuando visitaron Egipto (IV 126-133); Menelao le cuenta a Telémaco que se quedó anclado en la isla de Faros (o Faro) al volver a Egipto (IV 351-359), señalando que distaban un día de navegación ${ }^{47}$; y Odiseo, en su relato a Eumeo al volver a Ítaca (XIV 244-287), le cuenta que, después de la guerra de Troya, tras zarpar de Creta, atracaron en el «río Egipto», cuyas tierras gobernaba un solo rey ${ }^{48}$. Además de estas referencias explícitas, también se han señalado similitudes entre algunas de las costumbres griegas relatadas en la Odisea y las que recoge la documentación egipcia de la época ${ }^{49}$.

\section{Percepción de Egipto en la antigua Grecia}

Aunque los magi persas gozaban de considerable prestigio en la Hélade presocrática, la admiración por la grandeza del pueblo del Nilo, sobre todo en asuntos de religión, era algo patente en la antigua Grecia, hasta el punto de que muchos autores asociaban algunas de las prácticas de sus compatriotas a la influencia de las costumbres egipcias $^{50}$. En su Historia, Heródoto compilará a modo de etnólogo muchas de estas tradiciones, y dirá, siguiendo a las fuentes locales, que

los egipcios fueron los primeros hombres del mundo que descubrieron el ciclo del año, dividiendo su duración, para conformarlo, en doce partes. Afirmaban haberlo descubierto gracias a su observación de los astros. Y, en mi opinión, hacen un cómputo más ajustado que el de los griegos ... Decían también que los egipcios fueron los primeros en adoptar advocaciones para doce dioses -costumbre que los griegos tomaron de ellos- y los primeros en dedicar altares, estatuas y templos a los dioses $\mathrm{y}$ en esculpir relieves en piedra ${ }^{51}$.

47 Lo cual no es preciso, pero sirvió de orientación a Alejandro Magno para que fundase allí Alejandría, ciudad que en época de Plutarco (Alejandro 26. 5-7) ya había sido unida al continente por medio de un malecón.

48 Homero no lo llama faraón, sino B $\alpha \sigma \imath \lambda \varepsilon v ́ \varsigma$ (rey). Por otra parte, Homero da al río Nilo el nombre del país, Egipto, confundiendo ambas denominaciones. Sin embargo, tanto su descripción de la importancia de este río en la región, como la referencia al poder que recaía sobre un solo monarca, parece consistente con la realidad egipcia. Cf. Gómez Espelosín y Pérez Largacha (1997: 13-16).

49 Vid. Galán (2001), Gilbert (1939). Por lo demás, Egipto estará presente en la obra de autores posteriores a Hesíodo como Esquilo (Suplicantes, Prometeo Encadenado); y de geómetras presocráticos como Tales se dirá que aprendieron el arte de la matemática en Egipto (Aecio, De placitis I.3,1; Diógenes Laercio I.24).

50 Hartog (1986).

51 Heródoto, Historia II, 4, 1-3 (en traducción de Schrader 1992: 282-283). Es probable que la alusión a los doce dioses egipcios sea una perversión de los nueve tradicionales de la cosmogonía heliopolitana. El testimonio local que transmite Heródoto coincide con la percepción que los egipcios tenían de sí mismos según el relato de Unamón. Este relato transcurre en el siglo XI a.C., pero parece haber sido escrito posteriormente, durante la dinastía XXII, y en él se pone en boca de un fenicio el juicio de que la perfección y la sabiduría llegó a su país procedente de Egipto: «Ciertamente Amón ha suministrado las Dos Tierras al completo. Dotó a las demás después de haber suministrado a la tierra de Egipto de donde viniste. Así los artesanos salieron de ella para llegar al lugar donde estoy. Así las enseñanzas salieron de ella para llegar al lugar donde estoy» (El relato de Unamón, 2: 20-22, Papiro 120 del Museo Pushkin de Moscú, en traducción de Sánchez Rodríguez 2003: 243). En otro lugar, Hérodoto dice que los egipcios, «antes de que Psamético [663-609 a.C., fundador de la XXVI dinastía] reinara sobre ellos, se consideraban los hombres más antiguos del mundo; pero desde que Psamético al ocupar el trono, quiso saber qué pueblo era el más antiguo, desde entonces, consideran que los frigios son más antiguos que ellos y ellos más que los demás» (Heródoto, Historia II, 2, en traducción de Schrader 1992: 278-279). 
A pesar de la común tendencia a afirmar el origen divino de su estirpe ${ }^{52}$, los griegos solían conceder mayor longevidad a la cultura egipcia ${ }^{53}$, cuyas normas férreas y técnicas escriturales ${ }^{54}$ ayudaban a conservar la tradición; de ahí que, según el mito de la Atlántida que Platón relata en el Critias y en el Timeo, los griegos debiesen aprender de ellos para recordar su ancestral pasado ${ }^{55}$.

Inspirado por la organización egipcia del año, que era solar, frente al calendario lunar de los griegos, Platón propondrá en las Leyes que los ritos religiosos «no falten ninguno de los trescientos sesenta y cinco días $\rangle^{56}$, y en otros pasajes insistirá en la conveniencia de emular las técnicas educativas de los egipcios, que «primero aprenden con ayuda del juego y con placer operaciones de cálculo que los niños descubren simplemente ${ }^{57}$. La mayor eficiencia de su organización estatal se fundaría en una experiencia ancestral, pues el dios egipcio Theuth [Tot] habría sido el primero que «descubrió el número y el cálculo, y, también, la geometría y la astronomía, y, además, el juego de damas y el de dados. Y, sobre todo, las letras ${ }^{58}{ }^{5}$. Algunos de estos descubrimientos también les serán atribuidos por Aristóteles ${ }^{59}$, quien además dirá

52 Tucídides (Historia de la Guerra del Peloponeso I, 2-6) pensaba que, a diferencia del resto de los pueblos (los bárbaros, entre los que se incluirían los egipcios), el Ática habría sido el principal lugar apacible y próspero desde tiempos remotos, y ello gracias a la ausencia de migraciones.

53 Aristóteles, Política VII, 10,8, 1329b. Entre los historiadores era la opinión general al menos desde Éforo de Cime (s. IV a.C.), como recoge Diodoro Sículo, quien se muestra escéptico al respecto: «Los reyes existentes al comienzo ni nosotros mismos podemos explicarlos ni coincidimos con los historiadores que manifiestan conocerlos; es imposible que el descubrimiento de las letras sea tan antiguo que haya sido contemporáneo de los primeros reyes; $y$, aun si alguien lo admitiera, de todas maneras, el oficio de los historiadores parece establecido de modo totalmente reciente en la vida común. Además, sobre la antigüedad del género humano no solo discuten los griegos, sino también muchos bárbaros, pues dicen que son autóctonos y los primeros de entre todos los hombres que inventaron las cosas útiles para la vida y que los hechos acaecidos entre ellos fueron dignos de escritura desde más tiempo. Pero nosotros no podríamos definir la exactitud acerca de la antigüedad de cada uno ni qué pueblos preceden a los otros en el tiempo ni en cuantos años, sino que describiremos en lo principal lo dicho entre cada uno acerca de su antigüedad y de sus hechos primitivos, teniendo en cuenta la simetría. Trataremos primero acerca de los bárbaros no por creerlos más antiguos que los griegos, como Éforo ha dicho, sino porque queremos tratar antes la mayor parte de las cosas referentes a ellos, de modo que, una vez empezada la narración de la historia de los griegos, no introduzcamos en sus relatos antiguos ninguna acción heterogénea. Ya que se cuenta en el mito que el origen de los dioses tuvo lugar en Egipto y se dice que fueron descubiertas las más antiguas observaciones de los astros y, además de eso, se relatan en su historia hechos famosos y numerosos de grandes hombres, compondremos el principio de la historia con los hechos de Egipto» (Diodoro Sículo, Biblioteca Histórica I, 9, 2-6, en traducción de Torres Esbarranch 2004: 169-170).

54 Platón, Leyes II, 656d-e- 657a.

55 En el Timeo y en el Critias, Platón recurre a un mito en el que se relatan de manera caricaturesca dos perspectivas frente a la historia: la de un pueblo, el egipcio, de tradición milenaria y recuerdo ancestral, y la de otro, el griego, que, a pesar de considerarse la raza originaria (hija de los dioses Hefesto y Atenea, que los pastoreaban con justicia y les infundieron armonía en sus almas), se veía periódicamente abocado a la desmemoria debido a los cataclismos que asediaban su región. Dado que los que en cada ocasión sobrevivían «eran cerriles y analfabetos» (Platón, Critias 109d), los griegos debían reiniciar constantemente su historia y redescubrir la escritura. Aunque en otros pasajes desestime el valor de lo escrito frente a la oralidad, Platón era consciente de la importancia que tenía la escritura para que los conocimientos se conservasen de una generación a otra, y así considerará a los egipcios un pueblo de tradición escritural, mientras que los griegos serían un pueblo más volcado a la oralidad. Esta supuesta incapacidad griega para la memoria de largo alcance aparece expresada en el Timeo por boca de un sacerdote egipcio que exclama ante Solón: «¡los griegos seréis siempre niños! ¡no existe el griego viejo!» (Platón, Timeo 21e-22c, en traducción de Lisi 1992). Véase también Timeo 23a-25d.

56 Platón, Leyes VIII, 828b (en traducción de Lisi 1999: 78). En el siglo II a.C. aparecen en Atenas inscripciones que revelan el uso de ambos calendarios, pero el solar de 365 días no se impondría hasta el siglo XIV.

57 Platón, Leyes VII, 799a, 819b (en traducción de Lisi 1999: 29 y 65).

58 Platón, Fedro 274c-d (en traducción de Lledó 1986: 401-402).

59 Las Matemáticas en Metafísica 981b 23-25; la Astronomía en Sobre el cielo 292a. 
de Egipto que fue el primer país que se dotó de leyes, estructura política y clases sociales $^{60}$.

En otro orden de posibles referencias, cabría reseñar que, según Heródoto, en Egipto existía la creencia de que el sol había cambiado cuatro veces de dirección desde que la primera generación de reyes gobernase sobre la tierra. Heródoto cuenta que los sacerdotes egipcios de su época aseguraban que estos cambios no habían afectado al transcurso natural de los fenómenos, lo cual supone un matiz bastante extraño que nos hace sospechar que la postura de los sacerdotes -de ser cierto el testimonio de Heródoto (y asumiendo que les hubiese entendido)- corresponde al escepticismo de un periodo más crítico en el que los egipcios se cuestionaban algunos de los contenidos supersticiosos de su cultura ${ }^{61}$. Sea como fuere, de haber llegado esta creencia a la Grecia de Hesíodo, su lectura podría haber sido diferente, pues no se nos ocurre un evento astrológico más significativo que el supuesto cambio de rumbo del disco solar para que los antiguos hablasen (emic) del inicio de una nueva era: cuatro cambios en la posición del sol se podrían leer como cuatro mutaciones cósmicas que dividen la historia en cinco edades (cuatro pasadas más la presente); cada mutación supondría, además, un cataclismo con el que los dioses eliminaban la raza humana existente y daban vida a otra nueva ${ }^{62}$. En este punto, como es evidente, nos movemos en un terreno especulativo, pero cabe tener en cuenta que esta creencia pudo proporcionarle a Hesíodo una carcasa quinaria a partir de la que elaborar su mito.

\section{Hesíodo y la antigua literatura egipcia}

Al margen de estos testimonios más tardíos, es probable que algunos elementos de la antigua tradición egipcia hubiesen llegado a Grecia con anterioridad. Por ejemplo, Walcot ve en las pinturas egipcias de Deir el-Bahari (Hatshepsut, ca. 1490-1468

${ }^{60}$ «No parece ser un descubrimiento, ni actual ni reciente, de los que filosofan sobre el Estado, que debe separarse por clases la ciudad y ser distinta la clase militar de la de los agricultores. En Egipto, este estado de cosas existe aún ahora y también en Creta. En Egipto, según dicen, eso se remontaría a la legislación de Sesostris y en Creta a la de Minos... Fue, pues, allí [en Italia] donde se originó la institución de las comidas en común, pero la división del cuerpo cívico en clases procede de Egipto, pues el reinado de Sesostris es de una época muy anterior al de Minos. Así pues, se debe tal vez pensar que también las demás instituciones han sido inventadas muchas veces en el curso del tiempo, o mejor infinitas veces. En efecto, es verosímil que la necesidad enseñe a los hombres las cosas indispensables, y, una vez que existen éstas, lógicamente toman su desarrollo las relacionadas con el bienestar y la abundancia, y así también es necesario pensar que representan del mismo modo las instituciones políticas. Y que todas son antiguas, una prueba de ello es la historia de Egipto: los egipcios, que parecen ser los más antiguos, poseen sin embargo leyes y una organización política. Por eso es necesario utilizar convenientemente lo que se ha descubierto, e intentar investigar en lo que se ha dejado de lado» (Aristóteles, Politica VII, 10, 1-8, 1329b, en traducción de García Valdés 1988: 423-425). Por lo demás, se ha sugerido que algunas de las enseñanzas de la medicina hipocrática podrían proceder de Egipto. Cf. Jouanna (2012).

61 «... Según mis informadores, en el transcurso de once mil trescientos cuarenta años, ningún dios había aparecido en forma humana, y afirmaban que nada semejante se había producido, ni antes ni después, entre los demás reyes que hubo en Egipto. Además, aseguraban que, durante ese tiempo, el sol había cambiado cuatro veces de posición: en dos ocasiones había salido por donde ahora se pone y en otras dos se había puesto por donde ahora sale, sin que en el transcurso de esos años se alterara en Egipto nada, ni los beneficios que sus habitantes obtienen de la tierra y el rio, ni los síntomas de las enfermedades, ni las condiciones de la muerte» (Heródoto, Historia II, 142, 3-4, en traducción de Schrader 1992: 435).

62 Un mito similar se encuentra en los Aztecas, quienes al parecer dividían los mundos "históricos" en cinco, llamados soles, de los cuales ellos habitarían el quinto ( $c f$. Hastings, Selbie \& Gray, 1908: 183). Este mito, aunque filtrado por la periodización cristiana, pudo inspirar a Felipe Guamán Poma de Ayala su crónica peruana. Cf. Ossio 1977. 
a.C.) la representación más cercana a la descripción de la preparación de Pandora en la Teogonía de Hesíodo ${ }^{63} \mathrm{y}$, frente a la posibilidad de que esta tradición egipcia llegara a Grecia a través de Siria, sugiere que el contacto habría sido directo en un periodo posterior al 1570 a.C. En su opinión, el mito de Pandora que relata Hesíodo pertenece a la época pre-Doria y se podría rastrear en los restos micénicos que se introdujeron en la religión griega, pues hay una cantidad de evidencias considerable que sugiere que los reyes micénicos eran tan sagrados como los egipcios ${ }^{64}$. La influencia, pues, podría haber tenido lugar a través de la cultura minoica y, sobre todo, en el periodo micénico, donde existían prácticas y tradiciones tomadas de los egipcios. Un posible testimonio literario de este diálogo podría inferirse del mito de Dánao, el refundador de la micénica Argos que voló desde Egipto; un mito que, según fragmentos del Catálogo de las mujeres, parece conocido por Hesíodo: «Muy sedienta llama a Argos ... o también a partir de las Danaides que vinieron de Egipto y enseñaron a perforar pozos, según Hesíodo: “A Argos, que sin agua estaba, Dánao la hizo rica en agua" $\gg{ }^{65}$.

Otra de las posibles deudas de la obra de Hesíodo con la región del Nilo sería la literatura instructiva que desde el tercer milenio a.C. se cultivaba en Egipto. Los trabajos y los días, que Hesíodo dirige al agricultor Perses, tienen una clara impronta didáctica, pudiéndose incluir dentro del género de la parénesis (Adrados 1986). Ejemplos de estas composiciones se encuentran en el Rigveda 10.117, en el Mahabharata I, 142 (además de en el pasaje sobre las cuatro yugas; cf. III, 148-9), en las Instrucciones de Suruppak sumerias (de principios del tercer milenio a.C., el texto más antiguo del que se tiene noticia, aunque con versiones del 2.500 y del 1.800 a.C.), en los Consejos de sabiduría acadios (probablemente del periodo casita, 15001200 a.C.), en el libro de los Proverbios de Solomon hebreo, etc. Pero es en Egipto donde encontramos los mejores ejemplos: el más antiguo del que se conserva el texto completo es el de las Instrucciones de Ptahhotep (ca. 2.500 a.C. ${ }^{66}$, si bien existen otros muchos ${ }^{67}$. Estas obras se usarían como textos escolares durante siglos después de su composición, siendo habituales todavía en tiempos posteriores a Hesíodo.

\section{Egipto y el Mito de las Edades de Hesíodo}

Hace un par de décadas, Ludwig Koenen dio un nuevo enfoque al estudio de la influencia oriental en el Mito de las Edades de Hesíodo incidiendo en la literatura pro-

63 Walcot (1966: 68-69). El dios egipcio Khnum modeló a los seres vivos en la rueda del alfarero de modo semejante a cómo Aruru hizo a Enkidu y Hefesto a Pandora. El mito de Pandora, aunque con diferencias, también aparece en Los Trabajos y los Días justo antes de que comience el Mito de las Edades.

64 Walcot (1966: 71). Walcot (1966: 78-79) también observa similitudes entre el mito de Pandora y el mito egipcio de los hermanos Anubis y Bata, cuyos manuscritos datan de ca. 1225 a.C.

65 Eustacio, A Homero, 461, 2 (Hesíodo, Catálogo de las mujeres o Eeas, fr. 128 Merkelbach-West, trad. de Pérez Jiménez y Martínez Díez 1978: 206). Véase también Estrabón, VIII 6, 8.

66 Walcot (1966: 86). Una posible influencia en la distinción moral de las épocas podría proceder de la división egipcia del día en tres partes calificadas de buenas y malas, que fácilmente pudo trasladarse luego al año, pues al parecer los egipcios lo dividían también en tres estaciones.

67 Las Instrucciones de Kagemni, las Instrucciones de Hordedef, la Instrucción para Merikare (que reinó en Heracleópolis sobre 2100 a.C), la Instrucción de Amenemhet I, la Instrucción de un hombre a su hijo, la Instrucción de Sehetipibre, la Instrucción de Amen-em-Opet, la Instrucción de 'Onchsheshonqy, etc. Vid. West (1978: 3-25). Los textos se pueden encontrar en Lichtheim (1973-1980). 
fética precedente ${ }^{68}$. A su juicio, los paralelismos se darían en la descripción pesimista de la época vivida por el autor, la Edad de Hierro en Hesíodo, un mundo caótico en el que las normas morales se han pervertido ${ }^{69}$.

Lamentaciones por las penurias del presente, a veces combinadas con la advertencia de que el futuro puede ser todavía peor, están atestiguadas en algunos textos egipcios como la Profecía de Neferti (ambientada en el reinado de Seneferu, ca. 2.550 a.C., pero escrita ex eventu unos 600 años después) y en las Admoniciones de Ipuwar (ca. XIV a.C., o más antiguo). En estos textos se subraya el carácter violento de la época en que se vive o que está por venir, cuando la felicidad se desvanece y el egoísmo y la inmoralidad presiden las relaciones cósmicas y humanas, invirtiendo su orden natural (el sol ya no iluminará, el agua del río se convertirá en sangre, la tierra ya no será fértil, se vivirá en los cementerios, las mujeres sufrirán como sirvientes, el padre odiará al hijo y el hijo al padre, los hermanos se matarán entre sí, etc.). En cuanto a sus contenidos particulares, en la Profecía de Neferti destaca el anuncio de la llegada de un rey que restituirá el orden perdido (ex eventu, como ya dijimos), una creencia que al parecer formaba parte del ciclicalismo en el que se inscribía el ritual de sucesión egipcio: al morir un faraón -recuérdese su carácter divino- el nuevo rey debía reinstaurar el gobierno a partir del caos, como si se tratase del mismo Ra al inicio de una nueva cosmogonía, o del sol imponiéndose a la noche cuando amanece un nuevo día ${ }^{70}$. Aunque en Hesíodo no hay rastro de esta concepción profética (tampoco

68 Koenen (1994). Para un resumen: Rutherford (2009: 15-16). Rutherford solo añade la similitud entre el papel de Pandora en Hesíodo y el de Eva en el Génesis como desencadenantes de las calamidades humanas.

69 Entre los textos de este carácter de la época inmediatamente precedente, se han encontrado en el templo de Deir Alla (Palestina) unas inscripciones sibilinas escritas en arameo en torno al VIII a.C. en las que algunos sitúan una de las posibles fuentes comunes tanto de Hesíodo como de Daniel (Koenen 1994: 13 y n. 28); en este punto, Koenen sigue a Burkert. A juzgar por el texto de las tablillas que nos han llegado, la suposición nos parece excesiva: Texto I: «To you have come a smiter and a finisher,/ and they are the smiters of Pethor»; Texto II: «There was a damming up and the Jabbok became a smiter./ Strong and sudden (shocks) became a smiter»; Texto III: «The houses fell in heaps of ruins,/ and the spring poured'out covering them,/ and a curse was placed». En traducción de Shea (1989: 113).

70 «Señor, el grande ya no rige la tierra, / lo que fue hecho se ha deshecho, / ¡Ra debe empezar a recrear! / La tierra está completamente deteriorada, no quedan remanentes ... / Ahora, cuando la tierra sufre, a nadie le importa, / nadie habla, nadie derrama lágrimas ... / El disco solar, cubierto, ya no brilla para que la gente vea, / uno no puede vivir cuando las nubes lo encubren, / todo está entumecido en su ausencia ... / Toda la felicidad se ha desvanecido. / La tierra se ha doblegado a la angustia, / debido a esos ... / asiáticos que la recorren ... Los hombres empuñarán armas de guerra, / la tierra vivirá en tumulto. / Los hombres harán flechas de cobre, / cavarán sangre por pan, / se reirán con estruendo de las desgracias, / nadie llorará a los muertos, / nadie ayunará por los muertos, / cada corazón humano mirará (solo) por sí mismo. El luto ya no se practica hoy en día, / los corazones lo han abandonado por completo ... Te muestro al hijo como enemigo, al hermano como rival, un hombre matando a su padre ... Los hombres vivirán en el cementerio, el mendigo será rico, / el poderoso (robará) para vivir. / El pobre comerá pan, / los esclavos serán exaltados. / De la tierra se habrá ido el nombre de On, / el lugar de nacimiento de los dioses. / Luego, un rey vendrá desde el Sur, / Ameny, el legítimo, por nombre, / hijo de una mujer de Ta-Seti, niño del Alto-Egipto. / Él tomará la corona blanca, / él llevará la corona roja; / él unirá a las Dos Poderosas [Las dos tierras de Egipto], / él satisfará los deseos de los Dos Señores, / con el campo circundante en su puño y el remo aferrado. / ¡Alegraos, oh gente de esta época, / el hijo del hombre sellará su nombre para la eternidad! / Los malignos, los que maquinaron traiciones, reprimirán sus discursos temerosos de él; / los asiáticos sucumbirán a su espada, / los libios sucumbirán a su llama, / los rebeldes a su ira, los traidores a su poder, mientras las serpientes de su frente dominan a los rebeldes. / Alguien construirá las Murallas del Regidor, / para excluir a los asiáticos de todo Egipto; / ellos deberán pedir agua como mendigos, / así como para dar de beber a su ganado. / Entonces el orden volverá a su sitio, mientras Caos es desterrado» (Profecía de Neferti, traducida a partir de Lichtheim I, 1973: 141-144). Las premoniciones de luchas entre hermanos y padres e hijos también se encuentran en las Admoniciones de Ipuwer (1.5, 5.11), en las profecías del Shulgi sumerio y el dios Marduk babilonio, en el Oráculo del Potter helenístico, en Mateo (10.21) o en el iraní Bahman Yasht (II, 30). 
hay rastro de una concepción cíclica stricto sensu), en la descripción de su presente sí se encuentran paralelismos. Algo parecido sucede en las Admoniciones de Ipuwar, en las que el autor exclama cuánto desearía estar muerto y relata que los niños se lamentan de haber nacido en su época ${ }^{71}$ (recuérdese a Hesíodo: «ya no hubiera querido estar yo entre los hombres de la quinta generación sino haber muerto antes o haber nacido después» ${ }^{72}$ ). En este punto, según Koenen, Hesíodo estaría adaptando un topos que ya habían desarrollado los egipcios en textos antiguos ${ }^{73}$.

Por otro lado, la idea de una era arcaica en la que los dioses y los hombres convivían bajo el mandato divino también tenía un antecedente egipcio en el Mito de la Vaca Celeste (ca. 1400-1200 a.C.). El relato empieza así: «Sucedió en los tiempos en los que la Majestad de Ra, quien vino a la existencia por sí mismo, había ya establecido su poder tanto sobre los hombres como los dioses. En aquel entonces la Humanidad comenzó a conspirar contra él» ${ }^{74}$. Una de las primeras diferencias con el relato de Hesíodo es que la ruptura de la armonía primordial (una armonía que en este mito es cuestionable, pues poco se dice acerca de la época dorada) no es propiciada por una disputa entre dioses (Zeus destrona a Crono en el mito hesiódico), sino por una conspiración de los hombres contra el mandato de Ra. Pero en el mito egipcio aparece un elemento que sí tiene un correlato significativo en Hesíodo. El mito de la Isla de los Bienaventurados (o Afortunados, Makópılo) ${ }^{75}$, denominación que en Grecia encontramos por primera vez en el mito de las edades de Hesíodo (a ella envía Zeus a los Héroes que sobrevivieron a la cuarta edad ${ }^{76}$ ), tiene varios elementos comunes con los Campos de Juncos egipcios. Esta región mítica, de la que ya se encuentran menciones en los antiguos Textos de las Pirámides ${ }^{77}$, es lo más parecido a un edén

71 «Vino y Conquistó ... Lo que estaba ordenado para ti en la época de Horus, en la edad de [la Enéada]. [Ahora] los extranjeros se han convertido en ciudadanos por todas partes ... El crimen está por todas partes, ya no hay hombres de ayer... Todos dicen, "No sabemos qué le ha pasado a la tierra". / Señor, las mujeres son estériles, ninguna concibe, Knhum no labra debido al estado de la tierra ... Señor, el río es sangre ... / El oro escasea; los "materiales" necesarios para cualquier tipo de trabajo se han agotado ... Aquellos que eran ciudadanos ahora son extranjeros a los que uno debe mostrar el camino. / Señor, a todo el mundo [se le ha caído] el pelo, / uno no puede distinguir el hijo honorable del de los pobres. / Señor, uno está entumecido por el ruido, / ninguna voz se reconoce en estos años de gritos, / los alaridos no terminan. Señor, tanto grandes como pequeños dicen, "desearía estar muerto". Los niños exclaman: "No me debió traer a la vida!"» (fragmentos de las Admoniciones de Ipuwar a partir de Lichtheim I, 1973: 150-153). En esta -al parecer rica- tradición también se encuadrarían las Lamentaciones de Jajeperreseneb (ca. 1900 a.C.). Los lamentos por haber nacido se exclaman también en el Apocalipsis apócrifo de Baruch 10.6, donde se refiere a Jeremías 20.14, en el Apocalipsis de Esdras I. 21, o en el lamento de Job 3. El ruido ensordecedor como característica de un estado caótico también se encuentra en la canción acadia de Atrahasis (en ella, el ruido generado por los humanos motiva que Enlil intente destruirlos).

72 Hesíodo, Trabajos y días 174-175 (en traducción de Pérez Jiménez y Martínez Díez 1978: 133).

73 Koenen (1994: 17).

74 Mito de la Vaca Celeste, según inscripciones en la tumba de Sethy I (columnas 1-2), la versión más completa y mejor conservada. La traducción castellana es de Francisco López (2004) para egiptología.org. Lichtheim sólo traduce al inglés la primera parte; la edición más completa es la de la traducción alemana de Hornung (1997: 37-51). Cabe mencionar que en este cuento se describen algunas de las partes del dios-rey Ra en base a metales (plata, oro), aunque no en un contexto relevante para nosotros: «Su Majestad, había alcanzado la vejez y sus huesos eran de plata, su carne de oro y su cabello de verdadero lapislázul». La asociación de Ra-Sol con el oro era un topos común en el Antiguo Egipto ( $c f$. Aufrère 1997); papel similar tiene el oro en algunos pasajes védicos (vid. Gonda 1991).

75 Martínez (1999).

76 «Éstos viven con un corazón exento / de dolores en las Islas de los Afortunados, junto al / Océano de profundas corrientes, héroes felices a los que / el campo fértil les produce frutos que germinan tres / veces al año, dulces como la miel, [lejos de los Inmortales; / entre ellos reina Cronos» (Hesíodo, Trabajos y días 170-173).

77 Declaraciones 253, 266, 325, 479, 480, 507, 510, 519, 548, entre otras. Al parecer, Iaru o Aaru sería el Dios que reinaba en esta campiña de juncos (Declaración 308). 
paradisíaco $^{78}$ : en él vivirían los dioses y a él ascenderían los reyes afortunados tras la muerte.

El mito de la Isla de los Bienaventurados es prácticamente homólogo a los mitos de los Campos Elíseos y la Isla de las Hespérides, regiones fantásticas que tanto Homero como Hesíodo mencionan en otros lugares ${ }^{79}$. Nilsson ${ }^{80}$ cree que hay bastantes probabilidades de que éstos se puedan remontar a la época micénica, y que, por tanto, procedan de la cultura minoica ${ }^{81}$, la cual, a su vez, seguramente había adaptado elementos de la tradición egipcia.

The similarity of these Egyptian Islands of the Blest and Elysium is so striking that it hardly appears too bold to suppose that the Minoans borrowed the idea from Egypt just as they took over other Egyptian elements, which are especially conspicuous in the cult of the dead (...) The Greek Land of the Blest and its varying features are derived from the Minoan age and agree so closely with Egyptian conceptions that it seems probable that an intimate connexion may be supposed with Egyptian belief in this case ${ }^{82}$.

En los textos egipcios, el Campo de los Juncos se describe con las características de una región del Nilo idealizada (de abundante alimento, aguas puras, libre de trabajo) a la que el muerto llega si tiene éxito en su viaje hacia el más allás ${ }^{83}$ y se suele identificar con una región del Cielo cuyo acceso se encontraría en el extremo Oriente $^{84}$, lugar en el que Hesíodo localizaba la Isla de las Hespérides. Además, Hesíodo también describe este lugar (como Homero los Campos Elíseos) con las características del Olimpo divino, por lo que también se podría identificar con el Cielo.

Frankfort (1978: 120) ha señalado que el Campo de Juncos podría hacer referencia a la colina primigenia que surge de las aguas de Nun en las cosmogonías egipcias, un lugar donde se gestan la mayoría de los dioses, y que en algunos pasajes se llama «Isla de las Brasas» o «Campo en llamas». En este sentido, cabe tener en cuenta que, según la Teogonía de Hesíodo, Deméter, tras unirse con Yasión, da a luz a Pluto «en un fértil campo en el rico país de Creta» (Teogonía 969-974). Es decir, en el imaginario hesiódico, parece que existe cierta asociación entre la fertilidad divina y la isla de Creta. Además, aunque ésta no se identifique con la Isla de las Hespérides, y aunque Hesíodo no conociese de primera mano la geografía de Creta, algunos pasajes de la

78 En otros lugares, como el Libro de los muertos, también se denomina «Campo de las Felicidades» (cap. 18) o «Campo de la Eternidad» (cap. 79).

79 Homero, Odisea IV 560-569; Hesíodo, Teogonía 215-217, 516-517.

80 Nilsson (1927: 544-548).

81 «There is strong internal probability that this myth [el del Jardín de las Hespérides] goes hack to Mycenaean times, and is therefore ultimately derived from the Minoans ... It is generally recognized that the Gardens of the Hesperides are only another version of Elysium; both are proved to be derived from the Minoan Land of the Blest, but in this myth a new detail appears, the Tree of Life. The fable of a remote place of Bliss with a Tree of Life or a wonderful garden is, however, wide-spread. We have found it in Egypt associated with the Islands of the Gods and the Blest with their abundant supply of food and the wonderful sycamore, with the fruits of which both the gods and the Blest are nourished» (Nilsson 1927: 547).

82 Nilsson (1927: 548). Véase también Marinatos \& Anderson (2010).

83 Textos de las pirámides, Declaración 504; Libro de los muertos, cap. 99.

84 Textos de las pirámides, Declaración 325. También: «Ascenderás regularmente con Orión desde la región oriental del cielo, descenderás regularmente con Orión en la región occidental del cielo, el tercero de vosotros es Sotis, pura de tronos, y es ella quien os guiará sobre los hermosos caminos que están en el cielo, en el Campo de Juncos» (Declaración 442, "El rey muerto se convierte en una estrella", en traducción de López \& Thode 2003). 
Teogonía parecen aludir a cultos minoicos ${ }^{85}$. Por otro lado, según Diodoro Sículo, el mito de la edad de oro de Crono podría ser un invento de los cretenses ${ }^{86}$, quienes también representaban a un dios celeste portando un hacha, si bien su identificación con el Crono griego ha sido puesta en entredicho ${ }^{87}$.

La posición que ocupan los héroes ${ }^{88}$ en el mito hesiódico es la de haber precedido al poeta (v. 160), la cuarta estirpe y única sin metal característico. Aunque en Homero los héroes portaban, por lo general, armas de bronce ${ }^{89}$, es probable que la dignidad con la que reviste a la estirpe heroica (frente a la de bronce y la de hierro) esté inspirada en los valores que rigen las épicas homéricas ${ }^{90}$. Además, la época de Homero coincide con una explosión de los cultos heroicos en Grecia durante la que llegaron a abrirse tumbas antiguas del periodo submicénico y protogeométrico con el objetivo de descubrir los rasgos de los héroes fundadores ${ }^{91}$. Es el momento en que empiezan a consolidarse las ciudades-estado de la Grecia arcaica.

Entre los siglos XI y IX predominaba en Grecia una economía ganadera con asentamientos dispersos y elevados desde los que se dominaban las necrópolis. En esta época, los griegos comerciaban principalmente con los fenicios, gracias a cuyo intercambio conocieron materiales y técnicas extranjeras. En algún momento del siglo IX, la población se trasladó a nuevos asentamientos fortificados debido al tránsito hacia una economía agraria, coincidiendo con «la intensificación de la agricultura, que garantizaba una mayor productividad, y la necesidad creciente de reasignar tierras entre la población. Es el momento en que el hierro empezó a imponerse en útiles

85 Nilsson (1927: 459-460). Fernández (1986: 17) señala, siguiendo a Pausanias (IX 31, 4), que Hesíodo habría aprendido la mántica entre los acarnanios (Grecia Occidental), una región bastante alejada de Creta; aunque ello no impugna, claro, la posibilidad de otros viajes, ni la posibilidad de escribir sobre lugares sin haberlos visitado.

86 Cf. Diodoro Sículo, Biblioteca Histórica V 66, 1-6.

87 Véase la discusión en Nilsson (1927: 187, nota 1).

88 La idea de que en un momento de la historia el mundo estuvo dominado por semidioses engendrados por dioses y mujeres mortales se puede rastrear en el Génesis $(6,1-4)$ y otros textos en los que se dice que de su unión nació una estirpe de gigantes (Jubileos 5, 1-19; Josefo, Antigüedades de los judíos 1, 74). Koenen (1994) señala que, en el Catálogo de las mujeres atribuido a Hesíodo, la idea del fin de la era heroica tiene lugar con la muerte de los semidioses, y sugiere que la transferencia de algunos de ellos a la isla de los bienaventurados representa una suerte de contaminación de otras tradiciones del cercano oriente que distinguían dos edades del mundo: la presente fatigosa y la pasada gloriosa en la que cohabitaban hombres y dioses.

89 También de hierro (hachas, arcos), aunque la mayoría de las veces se lo relaciona con las armas de manera simbólica: por ejemplo, para hablar de la fuerza de Ulises, que parece hecho de hierro (Odisea XII 280), o para ilustrar la atracción que sienten los hombres por la guerra («es el hierro quien tira del hombre», Odisea XIX 13; «hierros de guerra brillantes, señal de matanza», XXI 4). En todo caso, el imaginario que describe a la estirpe férrea de Hesíodo ya estaría posibilitado por Homero. Por su parte, en el Catálogo de las mujeres no aparece el esquema de las razas metálicas. En él, el mundo de los héroes presenta los rasgos de la estirpe dorada del mito de las edades (fr. I. 6-13). Su fin llega con la Guerra de Troya, pero también parece acompañado por un cambio climático (fr. 204. 95-140). En caso de identificar a los héroes de la cuarta edad con los de las épicas de la Ilíada (guerra contra Troya) y la Tebaida (guerra de tebanos contra argivos), el autor estaría insuflando una dimensión histórica a su poema.

90 La identificación de la estirpe de Héroes con la época homérica ya fue sugerida por Lovejoy y Boas en 1935. No obstante, también los héroes de la Ilíada mencionan otros más fuertes que les habían precedido: (Habla Néstor) «Ya en otro tiempo con varones aún más bravos que vosotros tuve trato (...) y ellos nunca me menospreciaron. Pues todavía no he visto ni creo que vaya a ver a hombres como Piritoo, Driante, pastor de huestes, Ceneo, Exadio, Polifemo, comparable a un dios, y Teseo Egeida, semejante a los inmortales. Aquellos fueron los terrestres que más fuertes se criaron. Los más fuertes fueron y con los más fuertes combatieron, con las montaraces bestias, que de modo asombroso aniquilaron» (Homero, Ilíada I 260-268).

91 Carrière (1996: 414-415). De esta fiebre arqueológica-funeraria, sobre todo constatable en las regiones de la Argólida, Mesenia y el Ática, da testimonio el renovado culto a Agamenón en Micenas, o el de Menelao y Helena en Terapne. 
y armas y su demanda experimentó un aumento drástico con el fin de satisfacer las necesidades agrícolas y otras necesidades básicas $\gg{ }^{92}$. A partir de entonces se produjo un gradual crecimiento demográfico y, en torno al 750 a.C., se utilizarían nuevos lugares de culto y enterramiento que se diseminarían por todos los asentamientos, coincidiendo también con la separación del poder ritual y el poder político -antes fundidos en la figura del líder patriarcal-, y la aparición de templos y religiones de Estado organizadas en torno a una nueva clase dirigente y un ejército organizado. Kristiansen expone así el cambio sociopolítico al que Hesíodo habría puesto voz con nostalgia:

El ocaso del viejo orden y la formación de nuevos centros rituales vinculados a los principales asentamientos marcaron el comienzo de una nueva era: la de la polis y su gobierno comunal. Los antiguos líderes aristocráticos fueron derrocados y se formó una nueva clase dirigente con una base mucho más amplia de ciudadanos terratenientes libres, lo que introduciría un nuevo elemento de competencia por el poder, y también un factor de competencia entre las ciudades-estado por hacerse con el control del comercio, de los templos o de las ofrendas (ofrendas votivas). Más tarde muchos reconocieron este proceso como lo que realmente fue, un cambio rápido y profundo de un orden social secular, que provocaría un sentimiento nostálgico al que Hesíodo daría expresión a principios del siglo VII... Esta aparente nostalgia se evidencia en el culto al héroe en las antiguas tumbas micénicas. El culto al héroe empezó en la Edad Oscura pero se extendió con rapidez durante el siglo VIII, mientras que simultáneamente aparecían abundantes necrópolis y tumbas de nuevo cuño ... En esa confusión caleidoscópica de cambio tenía que haber algo que garantizara que una parte del viejo orden seguía presente -un anclaje al pasado-, y ésa fue precisamente la función del culto al héroe. Las tumbas antiguas inflamaron la imaginación, lo mismo que los hallazgos fortuitos, e incluso las excavaciones, como se aprecia en las fuentes escritas ... El culto al héroe nació del caldo de cultivo de la nueva división de tierras y de las consiguientes disputas, que dieron pie a la utilización de referencias a los ancestros para legitimar el derecho a la tierra... La épica, así como el culto al héroe, sirvieron para preservar valores comunes, algo sumamente necesario y relevante en un periodo de profundo cambio social, de migraciones temerarias y de expansión del comercio y de la guerra ${ }^{93}$.

Así pues, Hesíodo vivió en una época en la que se produjo un aumento real de la circulación y la demanda de objetos férreos, una época en la que también tuvo lugar un cambio profundo en el orden sociopolítico que propiciaría nuevos enfrentamientos por el gobierno de las polis y la reasignación de las tierras. Pero ello no quiere decir que antes no existieran estos problemas. Parte de la nostalgia del poeta se debería a la percepción indigerida de estos cambios, la cual, sumada a la fiebre epopeica en que vivía, motivaría los cortes metálicos que introdujo en su mito (al menos en lo que concierne a su presente de hierro frente a los periodos inmediatamente anteriores -las estirpes de Bronce y de Héroes-). Tal es la opinión de Nilsson, quien desestima la posibilidad de que Hesíodo readaptase un mito foráneo: «Hesiod kannte noch die Bronzezeit (v. 150), und aus dieser Kenntnis und der von Homer vorgebildeten und

Kristiansen (1998: 187-188).

Kristiansen (1998: 190-192). 
durch eigene Erfahrungen verstärkten pessimistischen Betrachtung des Verlaufs der Zeiten hat er sein Schema aufgebaut» ${ }^{94}$.

A nuestro juicio, en lo que se refiere a las edades de hierro, bronce y héroes, es muy probable que la construcción del mito hesiódico hubiera seguido los cauces referenciales de la propia cultura griega y minoica-micénica, como sugiere Nilsson, pero resulta más difícil explicar desde ella la necesidad del segundo periodo, el de la estirpe plata. Asumiendo que el relato de Hesíodo tenga de referencia los himnos homéricos, podría entenderse la necesidad de apelar a una época anterior a la de los héroes -a los que éstos se imponen, es decir, la de bronce-, para cuya imaginación también Homero aportaba materiales. Pero en esta dialéctica bastaría con postular sólo una estirpe más que la hubiera precedido (la de oro), a modo de origen divino que se le opone como referente moral. ¿Por qué dos más, entonces? Quizás encontremos algunas razones en la tradición egipcia.

\section{Las cinco estirpes de Manetón y las listas de reyes egipcias}

Las principales fuentes a las que Manetón recurrió para elaborar su Historia de Egipto fueron las listas reales, algunas de las cuales todavía conservamos ${ }^{95}$ : los cánones de Abydos y Karnak, que recogen la tradición del Alto Egipto, los cánones de Sakkâra y Turín, que recogen la tradición del Bajo Egipto, y la antigua Piedra de Palermo ${ }^{96}$. 1) Las inscripciones de la Piedra de Palermo, datadas en la V dinastía (ca. 2.600 a.C.), ofrecen el testimonio más antiguo de todos los conservados, y también una de las fuentes más probables de la tradición que recoge Manetón. 2) El Canon Real de Abydos (inscrito en una pared del corredor del Templo de Seti I, y del que se ha encontrado una copia mutilada en el Templo de Ramsés II) ordena cronológicamente setenta y seis reyes desde Narmer -Mênês- a Seti I -Sethôs- (omitiendo algunas dinastías). 3) El Canon Real de Karnak ofrece una lista de reyes (originalmente sesenta y uno) desde Narmer a Tuthmosis III (Dinastía XVIII). 4) El Canon Real de Sakkâra preserva las inscripciones de cuarenta y siete reyes (originalmente cincuenta y ocho) desde Miebis ( $6^{\circ}$ rey de la $1^{a}$ dinastía) hasta Ramsés II. 5) El Canon Real de Turín (ca. 1200 a.C.), el más completo e importante de todos ellos, contiene trescientos nombres de reyes y comienza con una serie dinástica de dioses y reyes mitológicos ${ }^{97}$. En este sentido, sólo la Piedra de Palermo (en la primera línea) y el Papiro de Turín (en las dos primeras columnas) ofrecen una lista de supuestos reyes anteriores a Narmer (fundador de la Dinastía I), por lo que seguramente Manetón -quien conjugaba cosmogonía mítica con cronología dinástica- seguía en su Aegyptiaca la tradición que legaban estas listas.

En el Canon de Turín se recogen las sucesivas generaciones de dioses y faraones que desde el principio de los tiempos habrían gobernado en Egipto: primero habría reinado $\operatorname{Ptah}^{98}$ [Hefesto, Vulcano], junto a la Gran Enéada heliopolitana, luego ven-

\footnotetext{
Nilsson (1955, I: 622, nota 1).

Cf. Redford (1986) y Kitchen (1991). Véase también Hornung (1966); Hornung (1982); Assmann (1985). Waddell (1964: XXI-XXIV).

Meyer (1904: 105).

98 Según Helck (1956: 5), originariamente, los textos se referirían a Ra en lugar de a Ptah, por lo que la lista respondería a una reconstrucción menfita de una jerarquía heliopolitana anterior. Ryholt (2004) calcula que el autor manejó un mínimo de cinco fuentes diferentes.
} 
dría la estirpe de Horus ${ }^{99}$ junto a los nueve semidioses de la Pequeña Enéada heliopolitana ${ }^{100}$, más tarde le tocaría el turno a los Espíritus benéficos, los «adoradores de Horus», y finalmente se iniciaría con Menes la larga lista dinástica de los reyes propiamente históricos. Es decir, de una primera estirpe de dioses, la lista de dinastías se va degradando (semidioses, adoradores de Horus) hasta dar paso a una estirpe de reyes mortales, la que constituirían los sucesivos faraones históricos. En este punto, a nuestro juicio, las similitudes con el mito hesiódico son considerables.

Por su parte, de Manetón nos dice Sincelo (fr. 2) que hablaba «de cinco estirpes egipcias que formaron treinta dinastías, que comprendían a aquellos a los que llaman dio-

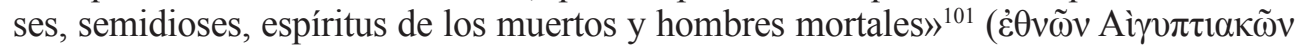

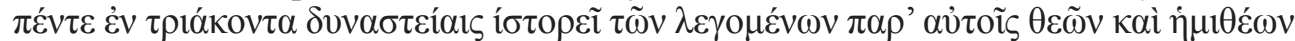

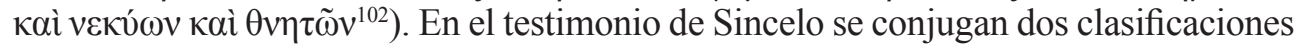
de seres: por un lado, el cronógrafo alude a cinco estirpes ( $\dot{\varepsilon} \theta v \tilde{\omega} v)$ egipcias originarias, pero a continuación enumera cuatro géneros de reyes: dioses, semidioses, espíritus de los muertos y reyes mortales. El término griego $\dot{\varepsilon} \theta v \tilde{o} v$ se podría traducir por nación o etnia, aunque también por estirpe, que precisamente es el término por el que generalmente se traduce el $\gamma \varepsilon ́ v o \zeta$ del texto hesiódico (además de por 'raza' o 'generación') ${ }^{103}$. En su trabajo canónico sobre Manetón, Waddell traduce è $\theta v \tilde{o} v$ por 'tribus' (tribes) $)^{104}$, como también Jiménez y Jiménez en otra versión española ${ }^{105}$, mientras que Adler y Tuffin, en su traducción de la Crónica de Sincelo, leen 'clases' (classes) ${ }^{106}$.

La precisión del término nos parece importante porque el quinarismo de las tribus originarias (también presente en el Rigved $a^{107}$ ) no coincide con la subsiguiente enumeración de dioses, semidioses, espíritus de los muertos y reyes mortales, que es la misma cantidad de géneros dinásticos que reporta Eusebio de Cesarea, aunque con ligeras variaciones en los nombres: Ex Aegyptiacis Manethonis monumentis, qui in tres libros historiam suam tribuit, - de diis et de heroibus, de manibus et de mortalibus regibus

99 O Haroeris. Vid. Helck (1956: 5, nota 8).

100 De la primera generación de Dioses de la cosmogonía de Manetón, Sincelo menciona solo seis: Hefesto, Helios, Agatodemon, Crono, Osiris y Tifón, por lo que no se podría hablar de Enéada; mientras que de la segunda estirpe, la de los semidioses, sí enumera nueve. En el Canon de Turín, en cambio, los primeros dioses serían diez (Ptah más la Enéada heliopolitana). Vid. Helck (1956: 4-5).

101 Carta a Ptolomeo II. Ps.-Manetho, FGrH 609 F 27. Versión castellana de Vidal Manzanares (1992: 21).

102 Manetón, fr. 2 (Syncellus, p. 73), en traducción de Waddell (1964: 10).

103 También en italiano se suele traducir $\gamma \varepsilon ́ v o \varsigma$ por 'stirpe'. Véase traducción de Ercolani (2010) y Cassammagnago

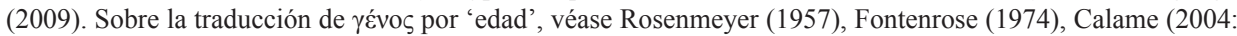
67-8) y Vaan Noorden (2015: 23 ss.). Bruno Currie (2012: 39-40) critica esta lectura.

104 Waddell (1964: 11).

105 Manetón, Historia de Egipto, trad. Jiménez Fernández y Jiménez Serrano (2008: 82). Siguiendo a Waddelll, leen 'tribus'.

106 Cf. Adler-Tuffin (2002: 55).

107 En el Rigveda se mencionan con frecuencia cinco tribus (1.117), pueblos (1.176) y razas (2.2) - pañca-janāh, pañca-krștáyah-, y los āryas se denominan raza quíntuple o pueblo quíntuple (p. e., 7.72), dividiéndose el mundo en cinco regiones (8.86). Además, siguiendo la lógica especulativa (de la tierra en el cielo y viceversa) se habla de «cinco tribus celestes» $(R v$. X.60.4). La identidad de estos cinco pueblos-tribus-razas es una cuestión disputada, aunque es probable que se refiera a las cinco tribus arias que conformaban -según Rigveda I.108.8- la sociedad védica de entonces (Anus, Druhyus, Yadus, Turvaśas y Pūrus) y que se distribuirían en cinco direcciones (páñca pradiśah): los cuatro cuartos (Diś) derivados del trazado de cuatro puntos cardinales más el centro en que intersecan. Dado que estas cinco tribus no parecen unidades sociales estables (pues en el Rgveda se mencionan cerca de treinta tribus diferentes), es probable que la frecuente definición en cinco viniese forzada por este discreto esquema "geométrico" de base. (La expresión «cinco pueblos» se aplicará en parte de la literatura posterior al conjunto de la humanidad, de modo similar a cómo los «cinco cuartos» expresarían en ocasiones el «todo esto» universal). Vid. 'Pañca-janāh' en Macdonell-Keith (1912, I: 466-8); Jamison \& Bereton (2014: 54); ‘Tribes’ en Parmeshwaranand (2000: 642-4). 
qui Aegypto praefuerunt usque ad regem Persarum Darium ${ }^{108}$. Es decir, dioses (diis), héroes (heroibus), manes (manibus) y reyes mortales (mortalibus regibus). Según las Selecciones latinas de Bárbaro, quien seguramente seguía a Africano (fr. 6), Manetón calificaba de «fortísimos» a «los reyes que fueron espíritus de los muertos, llamándolos también semidioses»» ${ }^{109}$, lo cual encajaría con la «estirpe» de héroes citada por Eusebio (¿la raza de los Héroes de Hesíodo?). Y estos espíritus de los muertos podrían identificarse con los shemsu Hor o adoradores de Horus a los que se refiere el Papiro de Turin $^{110}$. La cuestión es relevante porque, al parecer, en la época de Hesíodo también se distinguían cuatro clases diferentes de espíritus: los espíritus benditos que supervisan nuestras acciones (Trabajos y días 124-5), los démones del subsuelo, los muertos anónimos del Hades y los héroes felices de los campos Elíseos. Estos tipos de seres son, según Goldschmidt (1950: 36) Rosenmeyer (1957: 273) y Miralles (1975: 26) -aunque con diferencias entre ellos-, los que Hesíodo integra en su esquema vinculándolos a las cuatro generaciones que preceden a la de hierro ${ }^{111}$.

Entre los fragmentos de Manetón que nos han llegado, no hay ninguno en el que se mencione a Hesíodo, por lo que sería arriesgado atribuir estos paralelismos al influjo inverso (i.e., a la influencia del famoso mito de las cinco edades-razas en Manetón). Además, tampoco sus comentaristas cristianos lo tienen en cuenta a la hora de elaborar sus respectivas cronografías: Sincelo, a quien debemos el único fragmento que alude a las «cinco estirpes» de Manetón, sólo menciona a Hesíodo de pasada en la transcripción de textos ajenos ${ }^{112}$, entre los cuales el único significativo -aunque para nada vinculante- sería el de Flavio Josefo ${ }^{113}$. Por lo que todo apunta a que ni Sincelo ni Eusebio leían a Manetón desde las coordenadas del mito hesiódico.

\section{Conclusiones}

La intención de este artículo no es otra que la de agrupar una serie de reliquias, relatos e interpretaciones que pudieran ser útiles para el estudio de las periodizaciones primitivas, particularmente del mito de las edades de Hesíodo, el primer relato conservado en el que se divide la historia en cinco épocas. Nuestra motivación procede de no haber encontrado ningún trabajo que analizase la posible influencia egipcia en la estructura

108 Manetón, fr. 1, Eusebius, Chronica I (versión armenia), en edición de Waddell (1964: 2).

109 «... los cuales reinaron 2.100 años». Manetón, fr. 4, en traducción de Vidal Manzanares (1992: 23-24).

110 Edición de Vidal Manzanares (1992: 20, nota 4). Cf. Helck (1956: 6-7).

111 Contrariamente, Most (1997: 127) divide las razas metálicas en tres grupos: los de oro y plata serían añadidos divinos pre-humanos, mientras que el de bronce-héroes-hierro sería el esquema dialéctico inicial de razas humanas del que partió Hesíodo. Most defiende que la raza de los héroes y la de hierro pertenecen a la misma raza ( $\gamma \varepsilon \dot{v}$ o૬); la de hierro sería simplemente una generación posterior (actual) que echaba sus raíces en la heroica anterior. En respaldo de esto hablaría el hecho de que Hesíodo no dice que la raza de los héroes se destruya (como sí lo decía de las de oro, plata y bronce), pero resulta una hipótesis endeble.

112 Adler-Tuffin (2002: 58, 95, 250 y 257).

113 Aunque no cita ningún fragmento de su obra, lo enumera junto a otros autores cuya obra "confirmaría" la mayor longevidad de los antiguos patriarcas: «9... Y confirman mis palabras todos los griegos y bárbaros que escribieron libros que trataban de la antigüedad. En efecto, no solo Manetón, autor de un tratado sobre los egipcios, y Beroso, compilador de las tradiciones caldeas, sino también Moco, Hestieo, y además de estos el egipcio Jerónimo, quienes escribieron libros sobre los fenicios, están de acuerdo con lo que yo digo. También Hesíodo, Hecateo, Helánico, Acusilao, y además de estos Éforo y Nicolás cuentan que los primeros hombres vivieron mil años. Pero, en fin, sobre esto cada uno opine según le plazca» (Flavio Josefo, Antigüedades de los Judios I, 104: "Longevidad de los patriarcas: sus causas (Gen. 9, 28)"), en traducción de Vara Donado 1997: 38-39). 
del mito hesiódico, a pesar de la cantidad y variedad de estudios que suscita. Dado que no somos especialistas en mitología e historia antigua, ni tampoco filólogos, es probable que se nos escape alguna razón que justifique esta laguna, y que las hipótesis aquí propuestas hayan sido descartadas con fundamento por investigaciones que desconocemos. En todo caso, somos conscientes de la precariedad de las fuentes que manejamos, por lo que ponemos en manos de los expertos el dictamen sobre lo dicho.

De tener en el país del Nilo la principal "fuente originaria" de su estructura, lo más seguro es que los contenidos del mito de las edades de Hesíodo se hubieran recodificado a través de Creta, Micenas y Fenicia. La elección de los metales como elemento distintivo de las estirpes pudo propiciarla el mismo contexto en el que vivía el poeta, pero ello no explica que seleccionase solo cuatro para su mito, ya que sus coetáneos conocían algunos más ${ }^{114}$. Por otro lado, tampoco vemos necesario que el autor del Libro de Daniel se hubiese inspirado en el paradigma metálico de Hesíodo para idear su profecía, pues también en Egipto (antes que en el árbol de la profecía de Zoroastro) encontramos descripciones del cuerpo glorioso de Ra basada en metales.

Sea como fuere, entre las referencias egipcias que Hesíodo pudo tomar y someter a anamórfosis podríamos enumerar los siguientes: la creencia en una época arcaica en la que los dioses habrían convivido con los hombres llevaba siglos desarrollada en Egipto (Mito de la Vaca Celeste, Canon Real de Turín, Textos de las Pirámides). Asimismo, la teoría de la degradación de las sucesivas estirpes a partir de este origen divino también encuentra en Egipto algunos de sus paralelismos más significativos (Canon Real de Turín, Aegyptiaca). La posibilidad de la "actualización" de ese origen paradisíaco - actualización que Hesíodo representa con la Isla de los Afortunados regida por Crono, a donde se destinan los héroes victoriosos de la cuarta edad-tiene con la promesa egipcia del Campo de los Juncos del «más allá» unas similitudes considerables (Textos de las Pirámides, Libro de los muertos). Lo mismo cabría decir de los cuatro tipos de seres que distingue Manetón, pues recuerdan a los cuatro que, en el contexto griego, pudo tomar Hesíodo como referencia para sus razas. La identificación del rey egipcio con un dios sol de atributos áureos, aunque Hesíodo no la conociese directamente, podría inspirar la creencia en una remota estirpe divina. Su estética "dorada" podría haberse alimentado de los testimonios de los viajeros que habían visitado la región del Nilo, donde las impresionantes construcciones de piedra pareciese que brillan bajo el sol del desierto ${ }^{115}$. A nuestro juicio, incluso los artesanos de mitos buscan legitimar su discurso en datos positivos que luego distorsionan; y, en la época de Hesíodo, las listas de reyes egipcios ofrecían algunos de los registros más consistentes a partir de los que especular sobre pasados remotos.

Por lo demás, también en la cultura egipcia encontramos ejemplos abundantes de literatura instructiva y profética que podrían haberse conocido en la Grecia arcaica, así como pinturas que relatan mitos muy similares al de Pandora (Deir el-Bahari). Cuánto de estas tradiciones llegó directamente a la Grecia de Hesíodo y cuánto lo hizo a través de adaptaciones minoicas, micénicas o fenicias es algo sobre lo que no nos podemos pronunciar; pero, en todo caso, Hesíodo las habría recodificado desde los contenidos de su propia cultura en marcha.

114 Homero menciona el bronce 441 veces, el oro 300 veces, la plata 112 veces y el hierro 52 veces. En cambio, otros metales como el estaño sólo 10 veces, y el plomo 2 veces. Hesíodo, por su parte, menciona el oro 54 veces, el bronce 31, la plata 15, el hierro 8 y el estaño 2 ( $c f$. Most 1997: 125).

115 Los testimonios de estas tierras podrían venir de Creta, ya que de la primera mitad del primer milenio a.C. apenas se conservan registros de viajeros griegos en Egipto. $C f$. Macfarquhar (1966). 


\section{Bibliografía}

Adams, F. \& Laughlin, G. (1999), The Five Ages of the Universe. Inside the Physics of Eternity, New York, Simon \& Schuster.

Adler, W. \& Tuffin, P. (2002), The Chronography of George Synkellos. A Byzantine Chronicle of Universal History from the Creation, Oxford, University Press.

Adrados, F. R. (1986), «Las fuentes de Hesíodo y la composición de sus poemas», Emerita 54.1: 1-36.

Adrados, F. R. (2001), «La composición de los poemas hesiódicos», Emerita 69.2: 197-223.

Adrados, F. R. (2012), «Préstamo e innovación en la literatura griega: épica, lírica y teatro», Myrtia 27: 13-28.

Ángel y Espinós, J. (2007), «La presencia de Egipto en la pintura mural de Creta y Acrotiri», Boletín de la Asociación Española de Egiptología 17: 7-21.

Assmann, J. (1985), «Innovation und Restauration in der ägyptischen Literaturgeschichte», en H. U. Gumbrecht \& U. Link-Heer (eds.), Epochenschwellen und Epochenstrukturen im Diskurs der Literatur- und Sprachhistorie, Frankfurt, Suhrkamp: 484-499.

Aufrère, S. (1997), «L'univers minéral dans la pensée égyptienne: essai de synthèse et perspectives», Archéo-Nil 7: 113-145.

Baldry, H. C. (1952), «Who invented the Golden Age?», Classical Quarterly 2: 83-92.

Baldry, H. C. (1956), «Hesiod's Five Ages», Journal of the History of Ideas 17: 553-554.

Ballabriga, A. (1998), «L'invention du mythe des races en Grèce archaïque», Revue de l'histoire des religions 215: 307-339.

Bernabé, A. (2000), «Los mitos hititas sobre Kumarbi y la Teogonía de Hesíodo: semejanzas en la forma y diversidad de concepción religiosa», Cadmo 10: 147-166.

Bovet, M. de (1835²), Les dynasties égyptiennes suivant Manéthon, Avignon, Seguin Ainé.

Bueno, G. (1992), «Estado e Historia (en torno al artículo de Francis Fukuyama)», El Basilisco, $2^{\mathrm{a}}$ época, 11: 3-27.

Bueno, G. $\left(2016^{10}\right)$, El mito de la cultura, Oviedo, Pentalfa.

Bühler, G. (1886), Laws of Manu ('Sacred Books of the East', vol. 25), Oxford, University Press.

Burkert, W. (1992), The Orientalizing Revolution. Near Eastern Influence on Greek Culture in the Early Archaic Age, Cambridge-London, Harvard University Press.

Buttman, P. (1814), «Über den Mythos von den ältesten Menschengeschlechtern», en $M y$ thologus oder gesammelte Abhandlungen über die Sagen des Alterthums, II (1829): 1-27.

Calame, C. (2004), «Succession des âges et pragmatique poétique de la justice: le récit hésiodique des cinq espèces humaines», Kernos 17: 67-102.

Carrière, J.-C. (1996), «Le mythe prométhéen, le mythe des races et l'émergence de la citéétat», en F. Blaise, P. Judet de la Combe \& P. Rousseau (eds.), Le Métier du Mythe. Lectures d'Hésiode, Paris, Presses Universitaires du Septentrion: 393-429.

Cassanmagnago, c. (2009), Esiodo: Tutte le opere e i frammenti con la prima traduzione degli scoli, Milán, Bompiani.

Chandra Boy, P. (1884), Mahabharata, vol. II, Calcutta, Bharata Press.

Couloubaritsis, L. (1996), "Genèse et structure dans le mythe hésiodique des races», en F. Blaise, P. Judet de la Combe \& P. Rousseau (eds.), Le Métier du Mythe. Lectures d'Hésiode, Paris, Presses Universitaires du Septentrion: 479-518.

Crubellier, M. (1996), «Le mythe come discours. Le récit des cinq races humaines dans Les travaux et les jours», F. Blaise, P. Judet de la Combe \& P. Rousseau (eds.), Le Métier du Mythe. Lectures d'Hésiode, Paris, Presses Universitaires du Septentrion: 431-463. 
Currie, B. (2012), «Hesiod on Human History», en J. Marincola (ed.), Greek notions of the Past in the Archaic and Classical Eras: History without Historians, Edinburgh, Edinburgh University Press: 37-63.

Dalley, S. (1989), Myths from Mesopotamia. Creation, the Flood, Gilgamesh, and Others, Oxford, University Press.

Duchemin, J. (2000), Prométhée. Histoire du mythe, de ses origines orientales à ses incarnations modernes, París, Les Belles Lettres.

Duhoux, Y. (2003), Des Minoens en Égypte? «Kefiou» et «les îles au milieu du Grand Vert», Lovaina la Nueva, Université Catholique de Louvain.

Ercolani, A. (2010), Esiodo: Opere e giorni, Roma, Carocci.

Fernández Delgado, J. A. (1986), Los oráculos y Hesíodo. Poesía oral mántica y gnómica griegas, Cáceres, Universidad de Extremadura.

Fontenrose, J. (1974), «Work, Justice, and Hesiod's Five Ages», Classical Philology 69: 1-16.

Forbes, R. J. (1950), Metallurgy in Antiquity. A Notebook for archaeologists and technologists, Leiden, Brill.

Forbes, R. J. (1966²), Studies in ancient Technology, Vol. VII, Leiden, E.J. Brill.

Frankfort, H. (1978), Kingship and the Gods, Chicago/London, University of Chicago Press.

Froidefond, C. (1971), Le Mirage égyptien dans la littérature grecque d'Homère à Aristote, Aix-en-Provence, Ophrys.

Gaisford, T. (1816), Poetae minores Graeci, II. Scholia ad Hesiodum, Oxford, University Press.

Galán Allué, J. M. (2001), «La Odisea desde la Egiptología», Gerión 15: 75-97.

García Valdés, M. (1988), Aristóteles: Política, Madrid, Gredos.

Gardiner, A. H. (1987²), The Royal Canon of Turin, Oxford, Griffith Institute.

Gardner Wilkinson, J. (1851), The Fragments of the Hieratic Papyrus at Turin, London, T. Richards.

Gatz, B. (1967), Bodo, Weltalter, goldene Zeit und sinnverwandte Vorstellungen, Hildesheim, Olms.

Gilbert, P. (1939), «Homère et l'Égypte», Chronique d'Égypte 14, nº 27: 47-61.

Goettling, C. (1878³), Hesiodi carmina (ed. I. Flach), Leipzig, Teubner.

Goldschmidt, V. (1950), «Theologia», Revue des Études Grecques 63: 20-42.

Gómez Espelosín, F. J., \& Pérez Largacha, A. (1997), Egiptomanía, Madrid, Alianza.

Gonda, J. (1991), The Functions and Significations of Gold in the Veda, Leiden, Brill.

Griffiths, J. G. (1956), «Archaeology and Hesiod's Five Ages», Journal of the History of Ideas 17: 109-119.

Griffiths, J. G. (1958), «Did Hesiod invent the 'Golden Age'?», Journal of the History of Ideas 19: 91-93

Halleux, R. (1974), Le problème des métaux dans la science antique, Paris, Les Belles Letres.

Hartmann, W. (1915), De quinque aetatibus hesiodeis, Freiburg im B., Ex officina typographica caritatis (tesis doctoral).

Hartog, F. (1986), «Les Grecs égyptologues», Annales 41, №5: 953-967.

Hartog, F. (1990), «Écriture, Généalogies, Archives, Histoire en Grèce ancienne», en Mélanges Pierre Lévêque, tomo 5, Besançon, Université de Franche-Comté : 177-188.

Helck, W. (1956), «Untersuchungen zu Manetho und den Ägyptischen Königslisten», en H. Kees (ed.), Untersuchungen zur Geschichte und Altertumskunde Aegyptens, Berlin, Akademie-Verlag: 1-91.

Hornung, E. (1966), Geschichte als Fest. Zwei Vorträge zum Geschichtsbild der frühen Menschheit, Darmstadt, Wissenschaftliche Buchgesellschaft. 
Hornung, E. (1982), «Zum altägyptischen Geschichtsbewusstsein», Archäologie und Geschichtsbewusstsein. Kolloquien zur allgemeinen und vergleichenden Archäologie 3, München: 13-30.

Hornung, E. (199733), Der ägyptische Mythos von der Himmelskuh: Eine Ätiologie des Unvollkommenen, Göttingen, Vandenhoeck und Ruprecht.

Jakobsen, T. (1939), The Sumerian King List, Chicago, University of Chicago Press.

Jamison, S. W. \& Brereton, J. P. (2014), The Rigveda. The Earliest Religious Poetry of India, 3 vols., New York, Oxford University Press.

Jiménez Fernández, J. \& Jiménez Serrano, A. (2008), Manetón: Historia de Egipto, Madrid, Akal.

Jouanna, J. (2012), «Egyptian medicine and Greek medicine», cap. 1 en Greek Medicine from Hippocrates to Galen, Leiden, Brill.

Judson, O. P. (2017), «The energy expansions of evolution«, en Nature. Ecology \& Evolution, 1, Berlin, Springer.

Kamp, A. (2010), Vom Paläolithikum zur Postmoderne - Die Genese unseres Epochen-Systems, I. Von den Anfängen bis zum Aufgang des 17. Jahrhunderts, Amsterdam, John Benjamins Grüner Publishing Company.

Kitchen, K.A. (1991), «The Chronology of Ancient Egypt», World Archaeology 23: 201-208.

Koenen, L. (1994), «Greece, The Near East, and Egypt: Cyclic Destruction in Hesiod and the Catalogue of Women», Transactions of the American Philological Association 124: 1-34.

Kristiansen, K. (1998), Europa antes de la Historia. Los fundamentos prehistóricos de la Europa de la Edad del Bronce y la primera Edad del Hierro, trad. M. J. Aubert, Barcelona, ediciones Península.

Le Goff, J. (1991), El orden de la memoria. El tiempo como imaginario, Barcelona, Paidós Ibérica.

Leclerc, M.-C. (1993), «Le mythe des races», Kernos 6: 207-224.

Lichtheim, M. (1973-1980), Ancient Egyptian Literature, 3 vols., Berkeley, The University of California Press.

Lisi, F. (1992), Platón: Diálogos VI. Timeo, Critias, Madrid, Gredos.

Lisi, F. (1999), Platón: Diálogos VIII. Leyes, I-VI, Madrid, Gredos.

Lisi, F. (1999), Platón: Diálogos, IX. Leyes, VII-XII, Madrid, Gredos.

Livingstone, A. (2007), Mystical and Mythological Explanatory Works of Assyrian and Babylonian Scholars, Indiana, Eisenbrauns.

Lledó, E. (1986), Platón: Diálogos III. Fedón, Madrid, Gredos.

López, F. \& Thode, R. (2003), Los Textos de las Pirámides, www.egiptología.org.

Lovejoy, A. O. \& Boas, G. (1997), Primitivism and related Ideas in Antiquity, BaltimoreLondon, John Hopkins University Press.

Lucas, A. (1945), Ancient Egyptian Materials and Industries, London, Edward Arnold.

Macdonell, A. A. \& Keith, A. B. (1912), Vedic Index of Names and Subjects, 2 vols., London, John Murray.

Macfarquhar, C. F. (1966), «Early Greek Travellers in Egypt», Greece \& Rome 13: 108-116.

Marinatos, N. \& Anderson, A. S. (2010), «Elysion and Egypt», Journal of Ancient Egyptian Interconnections 2.2: 13-24.

Martínez, M. (1999), «Las Islas de los Bienaventurados: Historia de un mito en la literatura griega arcaica y clásica», Cuadernos de Filología Clásica (Estudios Griegos e Indoeuropeos) 9: 243-279.

Mazon, P. (1912), «Hésiode. La composition des Travaux et des Jours», Revue des Études Anciennes 14 : 329-356. 
Meltzer, E. S. (1974), «Egyptian Parallels for an Incident in Hesiod's Theogony and an Episode in the Kumarby Myth», Journal of Near Eastern Studies 33: 154-157.

Meyer, E. (1904), Aegyptische chronologie, Berlin, Verlag der König.

Meyer, E. (1910), «Hesiods Erga und das Gedicht von den fünf Menschengeschlechtern», en VV. AA., Genethliakon, Berlin, Weidmannsche Buchhandlung: 157-187.

Milán Quiñones, M ${ }^{\mathrm{a}}$ S. (2011), «Relaciones de Egipto con la Creta minoica», en VV.AA., Grecia ante los imperios. V Reunión de historiadores del mundo griego, Sevilla: 13-26.

Mills, L. H. (1887), The Zend-Avesta, III, Yasna, Afrinagan, Gahs and Miscellaneus Fragments, Oxford, University Press.

Miralles, C. (1975), «Hesíodo sobre los orígenes del hombre y el sentido del Trabajos y días», Boletín del Instituto de Estudios Helenísticos 9: 3-36.

Most, G. W. (1997), «Hesiod's Myth of the five (or three or four) races», Proceedings of the Cambridge Philological Society 43: 104-127.

Moyer, I. S. (2002), «Herodotus and an Egyptian Mirage. The Genealogies of the Theban Priests», The Journal of Hellenic Studies 122: 70-90.

Moyer, I. S. (2011), Egypt and the Limits of Hellenism, Cambridge, Cambridge University Press.

Neschke, A. (1996), «Dikè. La philosophie poétique du droit dans le 'mythe des races' d'Hésiode», en F. Blaise, P. Judet de la Combe \& P. Rousseau (eds.), Le Métier du Mythe. Lectures d'Hésiode, Paris, Presses Universitaires du Septentrion: 465-478.

Nilsson, M. P. (1927), The Minoan-Mycenaean Religion and the Survival in Greek Religion, London/Paris/Oxford/Leipzig, Lund.

Nilsson, M. P. (1955), Geschichte der griechischen Religion, München, C. H. Beck.

Nilsson, M. P. (1961), Greek folk religion, New York, Harper Torchbooks.

Ossio, J. M. (1977), «Las cinco edades del mundo según Felipe Guamán Poma de Ayala», Revista de la Universidad Católica de Lima 2: 43-58.

Pabón, J. M. (1982), Homero: Odisea, Madrid, Gredos.

Parmeshwaranand, S. (2000), Encylopaedic Dictionary of Vedic Terms, 2 vols., New Delhi, Sarup \& Sons.

Peinado, L. (2009), Libro de los muertos, Madrid, Tecnos.

Penglase, C. (1994), Greek myths and Mesopotamia, London-New York, Routledge.

Pérez Jiménez, A. \& Martínez Díez, A. (1978), Hesíodo: Obras y fragmentos, Madrid, Gredos.

Redford, D. B. (1986), Pharaonic king-lists, annals, and day-books, Mississauga, Benben.

Reitzestein, R. \& Schaeder, H. H. (1926), Studien zum antiken Synkretismus aus Iran und Griechenland, Leipzig, Teubner (Reseña crítica de Nock en 1929: Journal of Hellenistic Studies 49: 111-116).

Rochat, P. (2003), «Five levels of self-awareness as they unfold early in life», Consciousness and Cognition 12: 717-731.

Rosenmeyer, T. G. (1957), «Hesiod and Historiography», Hermes 85: 257-285

Roth, R. (1860), «Der Mythus von den fünf Menschengeschlechtern bei Hesiod und die indische Lehre von den vier Weltaltern», Tübinger Universitätsschriften aus dem Jahre 1860, II, Tübingen: 9-33.

Rutherford, I. (2009), «Hesiod and the literary traditions of the Near East», en Brill's companion to Hesiod, Leiden-Boston, Brill: 9-35.

Ryholt, K. (2004), «The Turin King List», Ägypten und Levante 14: 135-155.

Sánchez, A. (2003), La literatura en el Egipto Antiguo (Breve Antología), Sevilla, Egiptomanía. 
Sauzeau, P. \& Sauzeau, A. (2002), «Le symbolisme des métaux et le mythe des races métalliques», Revue de l’histoire des religions 219, n³: 259-297.

Schrader, C. (1992), Heródoto: Historia, II, Madrid, Gredos.

Shea, W. H. (1989), «The inscribed tablets from Tell Deir 'Alla, Part II», Andrews University Seminary Studies 27: 97-119.

Sinclair (1979), Hesiod: Works and Days, New York, Arno Press.

Solmsen, F. (1982), «The Earliest Stages in the History of Hesiod's Text», Harvard Studies in Classical Philology 86: 1-31.

Torres Esbarranch, J. J. (2004), Diodoro Sículo: Biblioteca Histórica, Madrid, Gredos.

Unger, G. F. (1867), Chronologie des Manetho, Berlin, Weidmann.

Vaan Noorden, H. (2015), Playing Hesiod: The 'Myth of the Races' in Classical Antiquity, Cambridge, Cambridge University Press.

Van der Pot, J. H. J. (1999), Sinndeutung und Periodisierung der Geschichte. Eine systematische Übersicht der Theorien und Auffassungen, Leiden/Boston/Köln, Brill.

Vara Donado, J. (1997), Flavio Josefo: Antigüedades de los Judios, Madrid, Akal.

Verbrugghe, G. P. y Wickersham, J. M. (1996), Berossos and Manetho, Introduced and Translated, Ann Arbor, University of Michigan Press.

Verdenius, W. J. (1985), A commentary on Hesiod Works and Days, vv. 1-382, Leiden, Brill.

Vernant, J.-P. (1960), «Le mythe hésiodique des races. Essai d'analyse structurale», Revue de l'histoire des religions 157 : 21-54. [Vernant, J.-P. (1973), «El mito hesiódico de las razas. Ensayo de análisis estructural», en Mito y pensamiento en la Grecia antigua, trad. J. D. López Bonillo, Barcelona, Ariel].

Vidal Manzanares, C. (1992), Manetón: Historia de Egipto, Madrid, Alianza.

Vv. Aa. (1908), «Ages of the World», en Hastings, Selbie \& Gray (eds.), Encyclopaedia of Religion and Ethics, vol. I, Edinburgh, T. \& T. Clark.

Waddell, W. G. (1964), Manetho: Aegyptiaca (epitome), London, William Heinemann.

Walcot, P. (1966), Hesiod and the Near East, Cardiff, University of Wales Press.

West, E. W. (1880), Pahlavi Texts, I, Oxford, University Press.

West, M. L. (1978), Hesiod: Works \& Days, Oxford, University Press.

West, M. L. (1985), The Hesiodic Catalogue of Women, Oxford, University Press.

West, M. L. (1999), The East Face of Helicon. West Asiatic Elements in Greek Poetry and Myth, Oxford, University Press.

West, M. L. (2003), Greek Epic Fragments. From the Seventh to the Fifth Centuries BC, LCL 497, London/Cambridge (Massachusetts), Harvard University Press.

Wilamowitz, U. von. (1928), Hesiodos erga, Berlin, Weidmann.

Youlan, F. (1989), Breve Historia de la Filosofía China, trad. Wang Hongxun y Fan Moxian, Pekín, Ediciones en Lenguas Extranjeras.

\section{Enlaces webs}

«Contents of the Royal Canon of Turin» en Pharaoh.se: https://pharaoh.se/royal-canon-ofturin-kinglist (consultado el 09.05.2020)

«Cosmogony and Cosmology. i. In Zoroastrianismo/Mazdaism» en Encyclopaedia iranica: http://www.iranicaonline.org/articles/cosmogony-i (consultado el 09.05.2020). 